\title{
EL REGIMEN DE LA AUTOINTOXICACION PLENA EN EL DERECHO PENAL CHILENO: DEUDA PENDIENTE CON EL PRINCIPIO DE CULPABILIDAD
}

\author{
Héctor Hernández. Basualto *
}

1. Situación legal y estado de la discusión; 2. El principio de culpabilidad en el contexto constitucional chileno; 3. Modelos de responsabilidad para la autointoxicación plena (y actio libera in causa); 3.1. El modelo de la excepción; 3.2. El modelo de la tipicidad; 4. Los límites operativos del modelo de la tipicidad; 5. Conclusiones y perspectivas de lege ferenda.

\section{Situación legal y estado de la discusión}

El viejo Código Penal chileno de 1874 no contiene ninguna norma que se haga cargo explícitamente de las consecuencias de la intoxicación para la responsabilidad por los hechos de relevancia penal realizados en ese estado. Con todo, se entiende pacíficamente que la decisión fundamental al respecto se encuentra en la regulación del trastorno mental transitorio $\mathrm{O}$, en nuestra terminología legal, de la "privación total de razón" como causa de exención de responsabilidad, en la segunda parte del art. $10 \mathrm{~N}^{\circ} 1 \mathrm{CP}$, donde, luego de eximirse de responsabilidad al "loco o demente", se exime de la misma también al que, "por cualquier causa independiente de su voluntad, se halla privado totalmente de razón".

Esta circunstancia -ausente en el modelo legislativo, del Código español de $1850^{1}$ - fue agregada a instancia del Comisionado Altamirano para darle "más latitud a su prescripción, comprendiendo otros varios casos análogos, como el del sonámbulo", con seguridad siguiendo en esto el juicio crítico de Pacheco ${ }^{3}$, y en términos inequívocamente tomados del Código español de $1822^{4}$. Y si bien se dejó expresa constancia de que esto se hacía "sin autorizar abusos como en el caso de

\footnotetext{
* Abogado, legum magister y Doctor en Derecho (Friburgo de Brisgovia), Profesor de Derecho penal y Derecho procesal penal, Universidad Jesuita Alberto Hurtado, Santiago de Chile.

${ }^{1}$ En esta parte el art. $8^{\circ} \mathrm{N}^{\circ} 1$ del Código español de 1850 se limitaba, en términos casi idénticos a los de la primera parte del art. $10 \mathrm{~N}^{\mathrm{o}} 1$ del Código chileno, a eximir de responsabilidad criminal al "loco o demente, a no ser que haya obrado en un intervalo de razón".

${ }^{2}$ Sesión $5^{\mathrm{a}}$, de 7 de mayo de 1870, Actas de las sesiones de la Comisión Redactora del Código Penal chileno, Imprenta de la República de Jacinto Núñez, Santiago 1873, p. 8.

3 Pacheco, Joaquín Francisco: El Código penal concordado y comentado (reedición de la tercera edición de 1867), Edisofer, Madrid 2000, p. 159 y s.

${ }^{4}$ Cuyo art. 26 rezaba: "Tampoco se puede tener por delincuente ni culpable al que comete la acción hallándose dormido, ó en estado de demencia ó delirio, ó privado del uso de su razón, de cualquiera otra manera independiente de su voluntad". Así también lo entendía Cousiño, Luis: Derecho penal chileno, Editorial Jurídica de Chile, T. III, Santiago 1992, p. 133.
} 
completa ebriedad", la propia formulación legal dejó inequívocamente establecido lo que no era más que un postulado en el modelo español ${ }^{6}$, esto es, que la intoxicación (ebriedad, embriaguez) plena ${ }^{7}$, en cuanto forma de privación total de razón, exime de responsabilidad penal, siempre que se deba a una causa independiente de la voluntad del sujeto. Con todo, es precisamente en virtud de esta última exigencia que puede sostenerse que, al menos desde el punto de vista de los inequívocos propósitos legislativos ${ }^{8}$ y del sentido que naturalmente fluye del texto legal, la autointoxicación, aunque sea plena, en cuanto será normalmente voluntaria, en general no exime de responsabilidad penal.

Sólo la intoxicación plena involuntaria, esto es, para usar los términos legales, la debida a causas independientes de la voluntad del sujeto, puede eximir de responsabilidad penal. Tal sería el caso, conforme a la opinión virtualmente unánime en nuestra doctrina, de la intoxicación forzada por terceros y de la intoxicación fortuita, por falta de conciencia en cuanto a la naturaleza de la sustancia, sea en términos absolutos, sea en términos relativos, como cuando sólo se ignoran factores accidentales que modifican sus efectos normales? ${ }^{9}$. En los demás casos de

\footnotetext{
${ }^{5}$ Sesión $5^{\mathrm{a}}$, Actas, p. 8.

${ }^{6}$ La total ausencia de referencias en el texto peninsular obligaba a Pacheco, Código penal, p. 223, a postular una absolución en virtud de los principios generales que ordenan la responsabilidad penal. No parece, sin embargo, que estas opiniones hayan sido consideradas por los redactores del Código chileno, como se desprende de su rechazo sin matices a cualquier consideración para con el ebrio.

${ }^{7}$ Desde luego no las etapas iniciales de la intoxicación que no suprimen las facultades requeridas por la imputabilidad penal. En principio puede decirse que la intoxicación que no alcanza a ser plena carece de toda relevancia en el derecho vigente, sin perjuicio de lo que se dirá a propósito de los alcohólicos y toxicómanos crónicos.

${ }^{8}$ Por si no fuera suficiente la ya mencionada constancia en la sesión $5^{\mathrm{a}}$, cabe recordar que en la sesión 120, de 21 de marzo de 1873, al preguntarse en el seno de la Comisión "si esta disposición comprende al que comete un delito en un caso de delirium tremens, producido por el exceso del licor, se resolvió unánimemente que no podría tener tal alcance, pues el artículo exige que la falta de razón provenga de causas totalmente independientes de la voluntad del hechor, lo que no sucede en el caso propuesto" (Actas, p. 216).

9 Así ya Fuensalida, Alejandro: Concordancias i comentarios del Código Penal chileno, Imprenta Comercial, Lima 1883, T. I, p. 48 y s.; Varas, Eduardo: Notas del curso de derecho penal, Universidad Católica de Chile, Santiago 1945, p. 200 y s.; Labatut, Gustavo: Derecho penal, T. I, 9º edición (a cargo de Julio Zenteno), Editorial Jurídica de Chile, Santiago 1989, p. 140 y s.; Novoa, Eduardo: Curso de derecho penal chileno, T. I, Editorial Jurídica de Chile, Santiago 1960, p. 478; Etcheberry, Alfredo: Derecho penal, $3^{\circ}$ edición, Editorial Jurídica de Chile, Santiago 1998, T. I, p. 287; Cury, Enrique: Derecho penal. PG, $7^{\circ}$ edición, Ediciones Universidad Católica de Chile, Santiago 2005, p. 426; Rivacoba y Rivacoba, Manuel de: El principio de culpabilidad en el Código penal chileno, en El mismo (editor): Actas de las Jornadas Internacionales de derecho penal en celebración del centenario del Código penal chileno, EDEVAL, Valparaíso 1975, p. 81; Brito, Haroldo / Fainé, Marcelo: La fórmula de la inimputabilidad en el Código penal chileno y la responsabilidad objetiva, en Rivacoba y Rivacoba (editor), Actas, p. 155 y s., 158, 162 y s.; Del Villar, Waldo: Manual de derecho penal. PG, EDEVAL, Valparaíso 1985, p. 170; Cousiño, T. III, p. 135; Garrido, Mario: Derecho penal, T. II, Editorial Jurídica de Chile, Santiago 1997, p. 225; Náquira, Jaime: Derecho penal T. I, McGraw-Hill, Santiago 1998, p. 371 y s.; Politoff, Sergio / Matus, Jean Pierre / Ramírez, María Cecilia: Lecciones de derecho penal chileno, PG, Editorial Jurídica de Chile,
} 
autointoxicación plena, por no ser aplicable la eximente del art. $10 \mathrm{~N}^{\mathrm{o}} 1 \mathrm{CP}$, lo normal será que el sujeto que realiza el tipo objetivo de un delito en ese estado sea sancionado como autor del delito doloso, con las penas asignadas al mismo y sin siquiera una atenuante ${ }^{10}$, no obstante haberse encontrado en una situación objetiva de inimputabilidad ${ }^{11}$.

El único desarrollo interpretativo en orden a matizar la rigidez de este marco legal que ha tenido efectos prácticos dignos de mención se ha verificado en relación con los alcohólicos crónicos. De la mano del reconocimiento del alcoholismo como una enfermedad, la jurisprudencia chilena ha mantenido de manera razonablemente constante la exención de responsabilidad penal del alcohólico crónico que actúa en estado efectivo de inimputabilidad (o una atenuación en los casos en que no se alcanza ese extremo), sea por la vía de afirmar que en estos casos la ingesta alcohólica que da lugar a la ebriedad no es controlable por el enfermo y, por ende, no es realmente voluntaria, sea por la vía de situar el caso en la primera parte del art. $10 \mathrm{~N}^{\circ} 1 \mathrm{CP}$, como una hipótesis de trastorno crónico ("locura o demencia") no sujeta en su tratamiento legal a la exigencia de ausencia de voluntariedad en sus causas, líneas de argumentación que, en todo caso, tienden a superponerse ${ }^{12}$. Lo mismo cabría esperar en general respecto del toxicómano, aunque no se conocen todavía sentencias al respecto. Por su parte, la doctrina se ha sumado al mismo predicamento ${ }^{13}$. Como resulta evidente, sin embargo, se trata

Santiago 2004, p. 313; Bullemore, Vivian / Mackinnon, John: Curso de derecho penal, Lexis-Nexis, Santiago 2005, T. II, p. 91. A pesar de su tono crítico, parece inclinarse ante el propósito legislativo Del Río, J. Raimundo: Derecho penal, Nascimento, Santiago 1935, T. II, p. 141; no se pronuncia, en cambio, en El mismo: Manual de derecho penal, Nascimento, Santiago 1947, p. 159 y s.

10 Es llamativo que el legislador chileno haya prescindido conscientemente de la circunstancia atenuante de intoxicación prevista en el modelo español. En efecto, en lo que aquí interesa, el art. $9^{\circ}$ $\mathrm{N}^{\circ} 6$ del Código español de 1850 consagraba como circunstancia atenuante la de "ejecutar el hecho en estado de embriaguez, cuando ésta no fuere habitual o posterior al proyecto de cometer el delito". Las razones que se tuvieron en cuenta para prescindir de la atenuante (sesión 8a , de 17 de mayo de 1870, Actas, p. 14) fueron, por una parte, las dificultades probatorias tanto para acreditar la embriaguez como su carácter habitual, y, por la otra, la decisión contraria consagrada por una ley patria que no se individualiza, pero que con seguridad era la de 20 de octubre de 1831 , cuyo art. $1^{\circ}$ rezaba: "En ningún caso se admitirá la embriaguez como escepción que exima al reo de la pena que la lei señala a los delitos cometidos en sana razón, i se deroga la parte de la lei $5^{\text {a }}$, título $8^{\circ}$, Partida $7^{a}$ que es contraria a la presente". Hasta donde se alcanza a ver, la temprana propuesta de Fuensalida, T. I, p. 81 y s., en orden a reconocer siempre una "eximente incompleta" (art. $11 \mathrm{~N}^{\circ} 1$ en relación con art. $10 \mathrm{~N}^{\circ} 1 \mathrm{CP}$ ) en casos de intoxicación plena voluntaria no ha tenido eco.

11 Así Novoa, T. I, p. 477; Cury, PG, p. 423; un panorama de la "larga y constante" jurisprudencia puede verse en Etcheberry, Alfredo: El derecho penal en la jurisprudencia, $2^{\circ}$ edición, Editorial Jurídica de Chile, Santiago 1987, T. I, p. 220 y ss.

12 El desarrollo en la jurisprudencia empieza temprano, con la sentencia de la CA Concepción, de 20 de diciembre de 1888 (GT 1888 II, s. 3383, 1323). Un panorama general puede verse en Etcheberry, El derecho penal en la jurisprudencia, T. I, p. 207 y ss.

13 Varas, Notas, p. 200; Del Río, Manual, p. 154, 159 (en El mismo, T. II, p. 141 aparentemente todavía sólo de lege ferenda); Labatut, T. I, p. 141; Novoa, T. I, p. 479 y s.; Etcheberry, T. I, 281; Cury, PG, p. 425; Cousiño, T. III, p. 135 y s.; Garrido, T. II, p. 225; Náquira, T. I, p. 372; Politoff / Matus / Ramírez, PG, p. 313. Desde el punto de vista médico-legal Politoff, Alberto: Intoxicación alcohólica e 
de un matiz importante pero más bien marginal, que no hace más que realzar la extraordinaria dureza del derecho vigente en la materia.

Desde antiguo esta solución general ha sido objeto de crítica por parte de la literatura científica. En la medida en que le resulta indiferente la situación concreta de imputabilidad del sujeto en el momento del hecho, se ve en ella, con razón, una solución incompatible con el principio de culpabilidad ${ }^{14}$. Ahora bien, mientras la crítica tradicional se ha limitado a constatar esta situación y a denunciar sus defectos, abogando por una rectificación de lege ferenda ${ }^{15}$, en los últimos tres lustros se ha comenzado a postular por parte de la doctrina una interpretación de lege lata, inaugurada por Garrido y continuada notoriamente por la literatura posterior, conforme a la cual la referencia a las causas independientes de la voluntad del agente en la privación total de razón sólo persigue excluir del ámbito de la exención de la responsabilidad las hipótesis de la llamada actio libera in causa ${ }^{16}$, si bien con la particularidad de que la culpa in causa sólo da lugar a una atenuación de la pena que corresponde por el delito doloso ${ }^{17}$. No se aprecia, sin embargo, que esta última posición haya recibido todavía aplicación jurisprudencial, de modo que puede seguir viéndose en ella más bien una propuesta alternativa de interpretación inserta en la crítica al derecho vigente.

Como se puede ver, más allá de esta diferencia de perspectiva, existe un importante grado de consenso en la doctrina chilena en cuanto a las deficiencias de la fórmula legislativa vigente y de los propósitos de sus redactores. Sea de lege lata,

imputabilidad, RCP T. XIX No 1 (1960), 97 (99 y ss. [pérdida del control -“voluntariedad”- de la ingesta en los alcohólicos], 103 [celotipia alcohólica, delirium tremens, alucinosis alcohólica y psicosis de Korsakoff como formas de "locura o demencia”]). En contra Fernández, Pedro Javier: Código penal de la República de Chile esplicado i concordado, $2^{\circ}$ edición, Imprenta, litografía i encuadernación Barcelona, T. I, Santiago 1899, p. 88, 103; y al parecer, en cuanto no distinguen, Bullemore / Mackinnon, T. II, p. 89 y s.

${ }^{14} \mathrm{Si}$ bien la ausencia de crítica a la solución legislativa es comprensible en obras que se limitan a exponer sumariamente el derecho vigente, llama la atención que autores de obras de mayor alcance y que dedican especial atención a los desafíos del principio de culpabilidad como Cousiño y Etcheberry se abstengan de toda crítica al respecto, con lo cual sugieren no ver contradicción entre dicho principio y la solución legal o la interpretación tradicional de la misma, a la cual, por lo demás, adhieren. A su favor puede decirse que tampoco parecen ver dicha contradicción autores que se han dedicado especialmente al examen de la compatibilidad de la legislación chilena con los principios de garantía propios del derecho penal, en particular con el mencionado principio de culpabilidad, como es el caso de Rodríguez, Collao, De la Fuente, Mera, o Künsemüller, en los trabajos que se citan en el apartado siguiente.

15 Fuensalida, T. I, p. 48; Del Río, T. II, p. 139 y ss.; Varas, Notas, p. 201; Novoa, T. I, p. 477 y s.; Cury, PG, p. 423 y s.; Rivacoba y Rivacoba, en El mismo (editor), Actas, p. 82; Brito / Fainé, en Rivacoba y Rivacoba (editor), Actas, passim, especialmente p. 160, 163.

16 Garrido, T. II, p. 224: "la finalidad de la norma es excluir la imputabilidad [sic, manifiestamente quiere decir inimputabilidad] únicamente del que se provoca ese estado en conocimiento de que puede delinquir. En otros términos, alude exclusivamente a la actio libera in causa"; de modo similar Náquira, T. I, p. 373; Politoff / Matus / Ramírez, PG, p. 313 y s.

17 Garrido, T. II, p. 224 y s.; Politoff / Matus / Ramirez, PG, p. 314. 
sea de lege ferenda, unos y otros están porque se reconozca al menos como principio general el carácter de inimputable y, consecuentemente, la exención de responsabilidad penal de quien se encuentra en una situación de intoxicación plena, cualquiera que sea su origen, y todo esto, se entiende hoy en forma mayoritaria, impuesto por el principio de culpabilidad. Tampoco parece haber diferencias realmente de fondo a la hora de juzgar la compatibilidad con dicho principio de la socorrida doctrina de la actio libera in causa, de importancia superlativa en la materia si se tiene en cuenta que para la mayoría -y no sólo para quienes ven en la defectuosa fórmula de la segunda parte del art. $10 \mathrm{~N}^{\circ} 1 \mathrm{CP}$ precisamente una consagración de la misma ${ }^{18}$ - dicha doctrina parece contener los criterios interpretativos adecuados para resolver satisfactoriamente la cuestión. En efecto, de entre los críticos sólo Cury ha estado por prescindir totalmente de tal construcción doctrinaria, pero sólo en atención a razones técnicas, por considerar que se trata de un conjunto de "nociones engorrosas y algo inútiles" que no van más allá que las reglas generales, y no porque se opongan al principio de culpabilidad, del cual, a su juicio, no importan excepción ${ }^{19}$.

Cabe mencionar, finalmente, que este relativo consenso, el que por lo demás se ha expresado nítidamente en el último esfuerzo prelegislativo del penalismo chileno ${ }^{20}$, concuerda con la que parece ser también la opinión

\footnotetext{
18 Es notoria la adhesión a la misma entre quienes se limitan a postular una rectificación de lege ferenda de la cláusula de inimputabilidad; así Novoa, T. I, p. 454 y s., 477 y s.; Rivacoba y Rivacoba, en El mismo (editor), Actas, p. 82; Brito / Fainé, en Rivacoba y Rivacoba (editor), Actas, p. 158 y ss.

${ }^{19}$ Cury, PG, p. 413. Paradójicamente, el único que entre nosotros ha alertado contra los potenciales peligros que para el principio de culpabilidad acarrea la doctrina de la actio libera in causa ha sido Cousiño, T. I (Santiago 1975), p. 535 y ss., quien al mismo tiempo, sin embargo, no tiene objeciones contra la formulación legal vigente.

${ }^{20}$ En efecto, el Anteproyecto de Nuevo Código Penal presentado en noviembre de 2005 por el Foro Penal (ANCP) dispone en su art. $6^{\circ} \mathrm{N}^{\circ} 2$ que está exento de responsabilidad penal “(e)l que, en forma transitoria, se halla privado totalmente de razón, siempre que dicho estado no se lo haya provocado para cometer el delito, ni su perpetración le haya sido previsible al momento de ponerse voluntariamente en dicha condición", se cita del Texto refundido y sistematizado del articulado aprobado en las deliberaciones de la Comisión Foro Penal, desde el 8 de mayo de 2003 hasta el 10 de noviembre de 2005. Sobre el Foro Penal puede consultarse Sepúlveda, Eduardo: Las iniciativas actuales para la reforma penal en Chile, Cuadernos Judiciales $\mathrm{N}^{\circ} 6$ (2002), 126 (128 y ss.); Etcheberry, Alfredo: El Foro Penal y el sistema de penas, Revista de Derecho (UCN - Coquimbo) No 9 (2002), 7 y ss.; Hernández, Héctor: El derecho penal chileno en el cambio de siglo, Persona y Sociedad, Vol. XVIII N N 2 (2004), 213 (232 y ss.). Con anterioridad, un criterio similar había sido recogido por el llamado Proyecto Erazo-Fontecilla de 1929, cuyo art. $7^{\circ}$ consagraba la inimputabilidad, entre otros, del que fuera "incapaz de apreciar el carácter de ilicitud de su hecho o de obrar en armonía con esa apreciación, a causa de trastorno del conocimiento, perturbación morbosa de sus facultades mentales o debilidad mental, retraso de su desarrollo mental por la sordomudez" $\left(\mathrm{N}^{\circ} 3\right)$, sin perjuicio de lo cual luego declaraba que "(s)erá, sin embargo, imputable el que se hubiere puesto, voluntariamente o por culpa, en estado de embriaguez o de inconsciencia, producido por efecto de substancias tóxicas o estupefacientes", citado del texto concordado y comentado de su Libro Primero, en el apéndice de Fontecilla, Rafael: La pena (evolución natural, jurídica y técnica). Los problemas modernos y sus influencias en el nuevo derecho penal chileno, Imprenta Cisneros, Santiago 1930, p. 235. No ocurría lo mismo, en cambio, con los Proyectos de 1938 (art. $20 \mathrm{~N}^{\circ}$ 2) y
} 
dominante en otros países de la región ${ }^{21}$ y viene en principio respaldado por textos legales de cierta influencia entre nosotros, como el español (sobre él infra 5).

Las páginas siguientes están destinadas a analizar críticamente este consenso, desde luego no en cuanto a la imperiosa necesidad de superar las consecuencias perjudiciales de una formulación legal manifiestamente deficiente y que interpretaciones bien intencionadas no han logrado evitar, sino en cuanto al régimen al que positivamente debiera someterse la cuestión de la autointoxicación plena en el derecho chileno y, en particular, al rol que en ese contexto debiera corresponderle a la doctrina de la actio libera in causa. Con esto no se está adelantando necesariamente una diferencia de fondo con el consenso imperante, sino sólo afirmando la necesidad de explicitar con mayor profundidad y precisión los términos del mismo, con plena conciencia de las delicadas implicaciones de principio que envuelve. Para decirlo desde ya con toda claridad: si bien la aplicación de la doctrina de la actio libera in causa representaría un indudable avance en relación con la situación del derecho vigente, no es en absoluto evidente que dicha doctrina -o más bien, las variantes realmente operativas de la misma- sea compatible con los principios cardinales del derecho penal, especialmente con el principio de culpabilidad ${ }^{22}$.

A continuación se abordarán los modelos disponibles para fundar una responsabilidad penal en casos de autointoxicación plena (infra 3 y 4), para luego, a partir de las conclusiones obtenidas, exponer unas reflexiones finales de lege ferenda (infra 5). Antes de eso, sin embargo, se situará la discusión en el contexto del reconocimiento constitucional del principio de culpabilidad en el derecho chileno (infra 2).

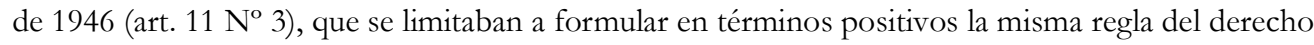
vigente.

${ }^{21}$ En la Argentina el art. $34 \mathrm{~N}^{\circ} 1 \mathrm{CP}$ no contiene excepciones a la exención de responsabilidad por inimputabilidad, lo que no ha sido obstáculo para que la jurisprudencia dominante, sin perjuicio de la crítica de la doctrina más reciente, aplique expresamente los criterios de la actio libera in causa, al respecto Iriarte, Ignacio en D'Alessio, Andrés (director): Código penal comentado y anotado, PG, La Ley, Buenos Aires 2005, p. 212 y ss., así como la selección jurisprudencial de Tozzini, Carlos en Baigún, David / Zaffaroni, Eugenio Raúl: Código penal y normas complementarias, Hammurabi, Buenos Aires 1997, T. I, p. 519 y s. De un modo similar, en el Perú, tampoco existen reglas especiales al respecto, sin perjuicio de lo cual se entienden aplicables -sin que se vea en ello una excepción a las reglas generales, en particular a la fórmula de inimputabilidad del art. $20 \mathrm{~N}^{\circ} 1 \mathrm{CP}-$ los criterios de la actio libera in causa, al respecto Hurtado Pozo, José: Manual de derecho penal, PG, $3^{\circ}$ edición, Grijley, Lima 2005, p. 634 y s.

22 Se comparte así el juicio al respecto del Instituto Interamericano de Derechos Humanos: Sistemas penales y Derechos Humanos en América Latina (Informe final), Depalma, Buenos Aires 1986, p. 37, que califica sólo como "mal menor" la doctrina de la actio libera in causa. 


\section{El principio de culpabilidad en el contexto constitucional chileno}

Antes de abordar el análisis de los modelos que permiten fundar la responsabilidad penal en los casos de autointoxicación plena, conviene detenerse en el status que ostenta el principio de culpabilidad en el régimen constitucional chileno. La cuestión no es menor si se tiene en cuenta que el principio de culpabilidad no tiene la misma fuerza en todos los ordenamientos jurídicos y que, precisamente tratándose de ámbitos problemáticos y altamente sensibles como es el de la autointoxicación, atendibles consideraciones de política criminal suelen propiciar una relativización del mismo.

Así, por ejemplo, en el derecho estadounidense existe un ámbito significativo de aplicación de responsabilidad objetiva (strict liability), de modo que no causa mayor extrañeza que, en particular, el régimen en materia de autointoxicación discurra sobre bases muy similares a las que se critican en el derecho chileno: la intoxicación suele constituir defensa idónea sólo cuando ha sido involuntaria ${ }^{23}$. Y en el ámbito continental la situación no es necesariamente muy distinta, como lo muestra un ordenamiento tradicionalmente tan influyente entre nosotros como es el italiano, en el cual, no obstante el generalizado reconocimiento de la jerarquía constitucional del principio de culpabilidad ${ }^{24}$, el art. 92 CP dispone que "(l)a ebriedad no derivada de caso fortuito o de fuerza mayor no excluye ni disminuye la imputabilidad" 25 . Más aún, ya se tendrá oportunidad de apreciar en este trabajo que ni aun en el ordenamiento penal español la cuestión es evidente (infra 5).

Por lo mismo, la afirmación de la jerarquía constitucional del principio de culpabilidad determina de modo decisivo el marco de la discusión, pues no se trata ya sólo de arribar a soluciones coherentes y razonables, sino que éstas deben ser, además, conformes a la Constitución.

\footnotetext{
${ }^{23} \mathrm{Al}$ respecto Dressler, Joshua: Understanding criminal law, 3rd edition, Lexis-Nexis, New York etc. 2001, p. 143 y ss. (strict liability), 319 y ss. (intoxication); para el derecho estadual, particularmente el de California, Méndez Longoria, Miguel Ángel: La intoxicación en el derecho penal estadounidense, Derecho Penal Contemporáneo No 13 (2005), 5. Al respecto puede verse también Piña, Juan Ignacio: La estructura de la teoría del delito en el ámbito jurídico del "Common Law", Comares, Granada 2002, p. 71 y ss., 130 y ss.

${ }^{24}$ A partir del art. 27 inciso primero de la Constitución italiana, que simplemente dispone que la responsabilidad penal es personal. Al respecto, en la manualística reciente, Cadoppi, Alberto / Veneriani, Paolo: Elementi di diritto penale, PG, CEDAM, Padova 2002, p. 96 y ss., con referencia a la sentencia de la Corte Constitucional de 24 de marzo de 1988.

${ }^{25}$ En tanto que, conforme al inciso segundo, la ebriedad preordenada al delito o a la preparación de una excusa opera como agravante. La constitucionalidad de la norma ha sido afirmada mediante sentencia de la Corte Constitucional de 4 de marzo de 1970, consultada en Longo, Piero / Ghedini, Niccolò (editores): Commentario constituzionale al codice penale e alle leggi di depenalizzazione, $2^{a}$ ed., CEDAM, Padova 2000, p. 56.
} 
La Constitución chilena de 1980, tal como ocurría con el texto de 1925 y es relativamente habitual en perspectiva comparada ${ }^{26}$, no contiene ninguna referencia expresa al principio de culpabilidad, sin perjuicio de lo cual la doctrina penal ha ensayado variadas líneas de argumentación para fundarlo, en términos similares a lo ocurrido en otros ordenamientos. Así, por ejemplo, se ha argumentado que el principio de culpabilidad es consecuencia obligada del reconocimiento constitucional de la dignidad humana (art. $\left.1^{\circ} \mathrm{CPR}\right)^{27}$, o bien del principio de irretroactividad de la ley penal (art. $19 \mathrm{~N}^{\circ} 3$ inciso séptimo CPR) ${ }^{28}$. Pero probablemente la línea argumentativa más influyente ha sido la desarrollada a partir de lo previsto en el inciso sexto del art. $19 \mathrm{~N}^{\circ} 3 \mathrm{CPR}$, donde se consagra que "(l)a ley no podrá presumir de derecho la responsabilidad penal". Pues, se ha sostenido, siendo la culpabilidad un presupuesto o requisito de la responsabilidad penal, presumir de derecho aquélla conlleva presumir del mismo modo esta última ${ }^{29}$. Al mismo tiempo se ha entendido al menos tácitamente que el recurso a prohibir que se "presuma de derecho" la culpabilidad no es sino una forma, algo imperfecta tal vez, de prohibir en general que se prescinda de ella, y con razón, en la medida en que toda forma de responsabilidad objetiva se deja formular en términos de una "presunción de derecho" 30 .

Debe reconocerse, sin embargo, que el recurso a la referida disposición resulta una base más bien precaria para fundar la jerarquía constitucional del principio culpabilístico. Y no, en todo caso, por su conocido origen en -muy

\footnotetext{
${ }^{26}$ Véase al respecto Bacigalupo, Enrique: La jerarquía constitucional del principio de culpabilidad, en El mismo: Principios constitucionales de derecho penal, Hammurabi, Buenos Aires 1999, p. 140 y ss.

27 Cousiño, T. III, p. 12 y ss., con referencias adicionales al principio del Estado de Derecho. También destaca la importancia de dicho reconocimiento, si bien más para fundar un determinado entendimiento de la culpabilidad que porque llevara implícita la consagración del principio de culpabilidad en el texto constitucional, Náquira, Jaime: Constitución Política y fundamento material del principio de culpabilidad, RChD Vol. 22 (1995), 189.

${ }^{28}$ Rodríguez Collao, Luis / De la Fuente, Felipe: El principio de culpabilidad en la Constitución de 1980, RDUCV XIII (1989-1990), 125 (131 y ss., 136).

${ }^{29}$ Rodriguez. Collao / De la Fuente, RDUCV XIII (1989-1990), 125 (139 y ss.); Cousiño, T. III, p. 15; Guzmán Dálbora, José Luis: Relaciones del derecho penal con el derecho constitucional, y su concreción en la Constitución Política chilena, Anuario de Filosofía Jurídica y Social 1994, p. 190 y ss.; Náquira, T. I, p. 323; Cury, PG, p. 388, 446 y s.; El mismo: Algunas consideraciones sobre el error de prohibición a la luz de la ley positiva chilena, en Jaén Vallejo, Manuel (director) / Reyna Alfaro, Luis (coordinador): Sistemas penales iberoamericanos. Libro homenaje al Prof. Dr. D. Enrique Bacigalupo en su 65 aniversario, ARA, Lima 2003, p. 716; menos categórico Mera, Jorge: Derechos Humanos en el derecho penal chileno, ConoSur, Santiago 1998, p. 114 y s. Véase también Künsemüller, Carlos: Culpabilidad y pena, Editorial Jurídica de Chile, Santiago 2001, p. 235 y ss.

${ }^{30}$ Sostiene una opinión diferente Etcheberry, T. I, p. 68, quien, si bien entiende la prohibición como una de presumir de derecho precisamente la culpabilidad, mantiene que la prohibición sólo alcanza a la específica forma de prescindir de la culpabilidad que es presumirla de derecho -lo que ahora lo lleva a reconocerle efecto eximente al error de prohibición invencible, p. 338-, quedando despejado, sin embargo, el camino para otras formas de prescindencia.
} 
confusas y en general lamentables- consideraciones procesales ${ }^{31}$, lo que, por cierto, no es obstáculo para que se extraigan de ella consecuencias para el derecho penal material, sino porque se trata de un razonamiento que tiene mucho de circular, en la medida en que da por descontado precisamente lo que se debe demostrar, esto es, que para la Constitución Política la culpabilidad es en efecto un presupuesto necesario de la responsabilidad penal ${ }^{32}$. En rigor, el argumento se funda más en el consenso doctrinario en torno al carácter irrenunciable de la culpabilidad para una atribución racional y justa de responsabilidad penal ${ }^{33}$ que en el texto constitucional. Desde luego no es éste un mal punto de partida para terminar afirmando la jerarquía constitucional del principio de culpabilidad en el contexto más general de la reconstrucción dogmática del estatuto constitucional del derecho punitivo chileno, pero, como bien señala Soto Piñeiro, todo parece indicar que esa tarea -que con seguridad no se agota en la interpretación de disposiciones aisladas y más bien supone una integración más compleja de principios y reglas- se encuentra todavía incompleta $^{34}$.

Con todo, y siquiera como estación hacia una más perfecta justificación de la jerarquía constitucional del principio, debe aplaudirse que esta línea de argumentación haya tenido gran acogida y que haya dado lugar a la inflexión experimentada - es de esperar que de modo definitivo- por la jurisprudencia

\footnotetext{
31 Con independencia de las fundadas dudas - de método y de legitimidad- en torno al valor hermenéutico que debe dársele a las actas de la llamada "Comisión Ortúzar", en la medida en que en este punto en particular se ha querido ver en ellas mucho más de lo que realmente hay (cfr. Cea, José Luis: La igual protección de los derechos, RChD Vol. 9 [1982], 521 [533 con nota 58]; Rodríguez. Collao / De la Fuente, RDUCV XIII [1989-1990], 125 [146 con nota 29]), debe aclararse que la discusión giró exclusivamente en torno a la eventual consagración constitucional de la presunción de inocencia, que en definitiva, como se sabe, no prosperó, a pesar del acuerdo de la Comisión. Lo pintoresco de este acuerdo es que los comisionados -temerosos en un comienzo de los alcances de la garantía- entendían consagrar una garantía fundamental que, sin embargo, no se oponía a que el legislador pudiera presumir la culpabilidad cuantas veces quisiera; lo único que se intuyó ilegítimo en ese contexto y al cabo de un debate tremendamente confuso fue que estas presunciones fueran "de derecho”, razón por lo cual se agregó el inciso que sí llegó a formar parte de la Constitución (Actas Oficiales de la Comisión Constituyente, sesiones 122, de 20 de mayo de 1975, pp. 25 a 32, 123, de 22 de mayo de 1975, pp. 4 a 22, y 124, de 27 de mayo de 1975, pp. 5 a 17). Es evidente que con esto, en la medida en que las "presunciones de derecho" quiebran la lógica procesal, se abre un camino para la interpretación del derecho sustantivo, del cual, sin embargo, los comisionados en su confusión conceptual manifiestamente no fueron conscientes.

32 Como lo destaca certeramente Soto Piñeiro, Miguel: Una jurisprudencia histórica: hacia el reconocimiento del "principio de culpabilidad" en el derecho penal chileno, RDUFT No 3 (1999), 233 (242), si bien entiende -y critica- que lo que se ha dado por descontado es la vigencia del principio de culpabilidad en la legislación chilena, extremo que, sin embargo, no es decisivo cuando se discute la jerarquía constitucional del mismo, a menos que se entienda, en la línea del argumento alternativo de Rodríguez. Collao / De la Fuente, RDUCV XIII (1989-1990), 125 (137 y ss.), que la Constitución al recoger el término "delito" ha incorporado en su sistema lo que por tal entiende la legislación ordinaria y su interpretación.

33 Así, expresamente, Cury, LH-Bacigalupo, p. 716 y s.

34 Soto Piñeiro, RDUFT No 3 (1999), 233 (242 y ss.).
} 
chilena desde fines de los años 90 en materia de culpabilidad ${ }^{35}$, hasta ahora básicamente en cuanto al reconocimiento del efecto exculpante del error de probibición invencible $e^{36}$, pero con un evidente potencial respecto de otras infracciones al principio de culpabilidad ${ }^{37}$, entre ellas, precisamente, la regulación de la autointoxicación plena. Porque el mismo razonamiento aplicado por la Corte Suprema a la falta de reconocimiento expreso del error de prohibición se debe aplicar a la fórmula de la privación total de razón, o al menos a su interpretación tradicional: siendo la imputabilidad requisito de la culpabilidad y ésta a su vez requisito de la responsabilidad penal, no admitir prueba sobre la privación total de razón o no asignarle relevancia a dicha prueba -o lo que en definitiva es, en términos sustantivos: no asignarle relevancia al estado de inimputabilidad del sujeto- implica presumir de derecho la imputabilidad y, en consecuencia, presumir de derecho la culpabilidad y la responsabilidad penal, que es precisamente lo que la Constitución proscribe.

En cuanto a los efectos prácticos de este juicio de contradicción con el ordenamiento constitucional, la ambigüedad de los términos legales -que ya ha permitido, como se ha visto, el desarrollo de una interpretación alternativa, al parecer respetuosa del principio de culpabilidad-probablemente permita que aquél se canalice a través de una "interpretación conforme a la Constitución" por parte de los tribunales ordinarios, sin necesidad de un pronunciamiento de inaplicabilidad o de inconstitucionalidad por parte del Tribunal Constitucional ${ }^{38}$, tal como, por lo demás, lo hizo la Corte Suprema respecto del error de prohibición invencible en la época en que concentraba aún el control represivo de constitucionalidad de las leyes.

En cualquier caso, sea que se requiera ineludiblemente la intervención legislativa, sea que se admita la posibilidad de una solución interpretativa, se hace necesario dilucidar los términos en que es posible fundar legítimamente una responsabilidad penal en casos de autointoxicación plena, esto es, sin infracción del principio de culpabilidad y, con ello, del ordenamiento constitucional.

\footnotetext{
${ }^{35}$ Hasta ese momento los esfuerzos de la doctrina no habían tenido mayor impacto en la práctica judicial, a excepción de meritorias pero aisladas resoluciones de algunas Cortes de Apelaciones. Mucho más significativos parecen haber sido los avances por la vía de la legislación ordinaria a partir del retorno a la democracia en 1990, la que, pese a su carácter muchas veces zigzagueante, fue suprimiendo los casos más flagrantes de infracción al principio de culpabilidad en la Parte Especial, particularmente las hipótesis más emblemáticas de calificación por el resultado.

${ }^{36}$ El giro se da con dos importantes sentencias de la Sala Penal de Corte Suprema, de 4 de agosto de 1998 (GJ 218 [1998], 96) y de 23 de marzo de 1999 (FM No 484 [1999], 187). Al respecto Soto Pineiro, RDUFT N 3 (1999), 233; Cury, LH-Bacigalupo, p. 719; El mismo, PG, p. 447.

37 Así, respecto de los delitos calificados por el resultado, Cury, PG, p. 388.

${ }^{38}$ De acuerdo con la nueva regulación prevista en el art. $93 \mathrm{~N}^{\circ} 6$ y $\mathrm{N}^{\circ} 7 \mathrm{CPR}$ desde las reformas constitucionales debidas a la Ley $\mathrm{N}^{\circ} 20.050$, de 26 de agosto de 2005.
} 


\section{Modelos de responsabilidad para la autointoxicación plena (y actio libera in causa)}

Estructuralmente los casos de autointoxicación plena se caracterizan por la sucesión de dos momentos: primero la provocación - en estado de imputabilidad- del "estado defectuoso", y luego -ya en ese estado- la realización inmediata de un tipo penal. Precisamente la existencia de ambos momentos constituye el punto de partida para los modelos con que se ha pretendido fundar en estos casos una responsabilidad penal por el tipo en cuestión. Mientras el llamado "modelo de excepción" quiere fundar la responsabilidad en la conducta en estado defectuoso que realiza directamente el tipo, prescindiendo de la inimputabilidad con que ha actuado el sujeto en atención a su conducta previa, el "modelo de la tipicidad" quiere fundarla directamente en dicha conducta previa ${ }^{39}$.

A continuación se analizan brevemente ambos modelos ${ }^{40}$, entendiendo que ellos pretenden responder al único problema de fondo envuelto en la autointoxicación plena, cual es si, de qué modo y en qué medida es posible fundar responsabilidad penal en estos casos. En ese contexto, la discusión sobre los alcances y el papel que en la solución del problema de fondo le corresponde a la doctrina de la actio libera in causa resulta ciertamente secundaria, sin perjuicio de lo cual, a propósito del examen crítico de los modelos en consideración, se tomará también posición al respecto. Como se puede ver, aquí se rechaza la tendencia generalizada, especialmente en la literatura comparada, de agrupar bajo la expresión actiones liberae in causa los casos de autointoxicación plena y otras situaciones de estructura semejante ${ }^{41}$, identificando de ese modo el problema con lo que parece no ser más que una propuesta de solución para el mismo, con todo el riesgo de confusión que ello implica ${ }^{42}$.

\footnotetext{
39 La denominación de los modelos provendría de Neumann, Ulfrid: Zurechnung und "Vorverschulden", Duncker \& Humblot, Berlin 1985, p. 24 y ss., texto que lamentablemente no se ha podido tener a la vista.

${ }^{40}$ Una excelente y exhaustiva visión general de los modelos, en castellano, ofrece Joshi Jubert, Ujala: La doctrina de la "actio libera in causa" en derecho penal (ausencia de acción o inimputabilidad provocada por el sujeto), J.M. Bosch, Barcelona 1992, p. 221 y ss.; la que puede complementarse con la más actualizada presentación de Alcácer, Rafael: Actio libera in causa dolosa e imprudente. La estructura temporal de la responsabilidad penal, Atelier, Barcelona 2004, p. 33 y ss.

${ }^{41}$ Las explicaciones que siguen valen en buena medida también para casos de provocación de incapacidad de acción, entre otros. En la medida en que, sin embargo, no pertenecen al objeto de este trabajo, se prescindirá de mayores referencias a los mismos.

${ }^{42}$ Se comparte así la crítica de Hruschka, Joachim: Strafrecht nach logisch-analytischer Methode, 2. Aufl., De Gruyter, Berlin - New York 1988, p. 48 y s., para quien la expresión se ha convertido en una "palabra mágica" de contenido difuso. Representativo es el caso de Joshi Jubert, Actio libera, p. 13. No puede desconocerse que, a diferencia de muchos otros, esta autora distingue enfáticamente entre concepto, ámbito y solución de la actio libera in causa (p. 116 y ss.), pero en la medida en que los términos no dan cuenta por sí mismos de tal distinción y que la discusión a su respecto no es precisamente un ejemplo de claridad, su empleo sigue pareciendo inconveniente.
} 


\subsection{El modelo de la excepción}

Si se tiene en cuenta que en los casos de autointoxicación plena la realización directa del tipo penal corre por cuenta de la conducta en estado defectuoso, resulta natural que la responsabilidad por ese determinado título de imputación se quiera fundar precisamente en dicha conducta. Como se trata, sin embargo, de una conducta realizada en estado de inimputabilidad, el modelo se ve obligado a hacer una excepción al principio de culpabilidad por el hecho en el caso particular, sin la cual sólo cabría la absolución. Las razones que justificarían la excepción se encuentran en la circunstancia de haber sido el propio sujeto quien se ha puesto voluntariamente en el estado defectuoso, sea que lo haya hecho con el deliberado propósito de delinquir, sea que, al menos, haya sido previsible esa consecuencia. Pues, se argumenta, el respeto en este caso del principio de culpabilidad implicaría legitimar un abuso de derecho (fraude de ley), extremo que la garantía no exige ${ }^{43}$. Como se ve, si bien no se reprime la actio praecedens, ella aporta el fundamento para la represión excepcional de la conducta defectuosa.

Este modelo es el que mejor responde tanto al origen histórico como al sentido literal de la fórmula que sintetiza la doctrina de la actio libera in causa. En efecto, se castiga excepcionalmente por la conducta en estado defectuoso, no libre, en razón de que en su origen sí lo fue, con lo cual, si bien no se trata de una actio libera in se, como ocurre en la generalidad de los casos, es de todas maneras una actio libera-libera in sua causa- y en esa medida equiparada valorativamente a la anterior ${ }^{44}$. Para decirlo en los tan categóricos como convincentes términos de Hruscbka: la actio libera in causa lisa y llanamente es el modelo de la excepción ${ }^{45}$.

Debe reconocerse que desde la perspectiva de la verificación de la tipicidad y de la antijuridicidad en el caso concreto, en cuanto se centra precisamente en la conducta que realiza directamente el tipo, el modelo tiene en principio la ventaja

\footnotetext{
43 Muñagorri, Ignacio: Sobre la presencia de la "actio libera in causa" en el art. 8.1 del Código Penal, ADPCP 1991, 413 (443); Bustos, Juan / Hormazáabal, Hernán: Lecciones de derecho penal, Trotta, Madrid 1999, Vol. II, p. 355 y s.; Díaz Pita, María del Mar: Actio libera in causa, culpabilidad y Estado de Derecho, Tirant lo Blanch, Valencia 2002, p. 184 y ss. Más parca Alonso Álamo, Mercedes: La acción "libera in causa", ADPCP 1989, 55 (66 y s.): el enlace causal y psicológico entre ambas conductas funda la necesidad de pena.

44 Al respecto, con detalle, Hruschka, Joachim: La imputación ordinaria y extraordinaria en Pufendorf. Sobre la historia y el significado de la diferencia entre actio libera in se y actio libera in sua causa [1984] (trad. Pastor), en El mismo: Imputación y derecho penal. Estudios sobre la teoría de la imputación, Thomson - Aranzadi, Elcano 2005, p. 56 y ss.; El mismo: Strafrecht nach logischanalytischer Methode, p. 343 y ss.; El mismo: Probleme der actio libera in causa heute, JZ 1989, 310 (310 y ss.); El mismo: Die actio libera in causa - speziell bei \20 StGB mit zwei Vorschlägen für die Gesetzgebung, JZ 1996, 64 (65); El mismo: Die actio libera in causa bei Vorsatztaten und bei Fahrlässigkeitstaten, JZ 1997, 22 (23); El mismo: Actio libera in causa y autoría mediata [2002] (trad. Joshi Jubert / Bolea Bardón), en El mismo: Imputación, p. 157 y ss.

${ }^{45}$ En último término, entre muchas otras ocasiones, Hruschka, Actio libera in causa y autoría mediata, p. 168.
} 
de permitir una aplicación muy "natural" de tales categorías dogmáticas, sin perjuicio de las dificultades -que pueden ser muy considerables- que trae aparejada la necesaria consideración conjunta de aspectos tanto de la actio praecedens como de la conducta en estado defectuoso, lo que es particularmente nítido en el plano subjetivo $^{46}$. Por otra parte, al menos a primera vista, la justificación de una excepción al principio de culpabilidad podría parecer plausible.

No obstante todo esto, se trata, sin embargo, de una solución incompatible con un genuino derecho penal de culpabilidad ${ }^{47}$, pues por razonable que pueda parecer la excepción, el dato ineludible que queda en definitiva es el de la imposición de una sanción penal a un sujeto por conductas realizadas en circunstancias en que reconocidamente no ha podido ajustar sus actos a los mandatos del derecho ${ }^{48}$. La referencia a la actio praecedens plenamente imputable como justificación de esta consecuencia, no hace más que reforzar las semejanzas con la estructura del razonamiento que subyace a toda forma de versari in re illicita: "si te autointoxicas plenamente, atente a las consecuencias"49.

Por lo mismo, no resultan convincentes los intentos de salvar la incompatibilidad con el principio culpabilístico haciendo referencia a otras situaciones en las que se admitirían sin discusión excepciones al efecto de una circunstancia eximente, excepciones que también se fundarían en el actuar precedente reprochable del sujeto, como sería el caso del error de prohibición cuando es vencible ${ }^{50}$, entre otros supuestos ${ }^{51}$. Sin embargo, las situaciones son

\footnotetext{
${ }^{46}$ Como lo sugieren las reflexiones de Alonso Álamo, ADPCP 1989, 55 (94 y ss.); y Joshi Jubert, Actio libera, p. 396 y ss.

47 Sin contar con la potencial infracción al principio de legalidad, en países cuya legislación no contempla ninguna excepción, como ocurre, por ejemplo, en el derecho alemán. Con todo, ése es un aspecto que puede salvarse fácilmente con la intervención del legislador, no así la compatibilidad con el principio de culpabilidad. No ven, sin embargo, obstáculos para la intervención del legislador, entre otros, Salger, Hannskarl / Mutzbauer, Norbert: Die actio libera in causa - eine rechtswidrige Rechtsfigur, NStZ 1993, 561 (565); Ambos, Kai: Der Anfang vom Ende der actio libera in causa?, NJW 1997, 2296 (2298).

48 Roxin, Claus: Observaciones sobre la "actio libera in causa" [1987] (trad. Muñoz Conde), ADPCP 1988, 21 (24); Hirsch, Hans Joachim: Acerca de la actio libera in causa [1998] (trad. Demetrio Crespo), en El mismo: Derecho penal. Obras completas, T. I, Rubinzal-Culzoni, Buenos Aires 1998, p. 181; Jakobs, Günther: La denominada actio libera in causa [1998] (trad. González Rivero), en El mismo: Dogmática del derecho penal y la configuración normativa de la sociedad, p. 220 y ss.; Joshi Jubert, Actio libera, p. 355; Alcácer, Actio libera, p. 99 y s.

${ }^{49} \mathrm{Ha}$ destacado recientemente este paralelismo estructural entre versari in re illicta $\mathrm{y}$ actio libera in causa, en una perspectiva histórica, Hormazábal, Hernán: La doctrina de la actio libera in causa y su incorporación al derecho español, en Diez Ripollés, José Luis et al (editores): La ciencia del derecho penal ante el nuevo siglo. Libro Homenaje al Prof. Dr. D. José Cerezo Mir, Tecnos, Madrid 2002, especialmente p. 803 y ss.

50 También entre nosotros se admite mayoritariamente que el error vencible no exime de responsabilidad, véase por todos Cury, PG, p. 448.

51 Así, por todos, Hruschka, JZ 1989, 310 (313); JZ 1996, 64 (68); JZ 1997, 22 (24). En la literatura alemana se suele mencionar en este contexto también el caso del estado de necesidad exculpante cuando
} 
difícilmente comparables dado el muy diverso efecto que tienen las distintas eximentes en el conjunto de las capacidades del sujeto ${ }^{52}$. En efecto, con independencia de que se pueda argumentar de modo más o menos convincente que en estos casos en rigor no se está en presencia de un reproche por hechos previos $^{53}$, todo parece indicar que en la inimputabilidad se alcanzan ciertos límites de las posibilidades de funcionalización del concepto de culpabilidad, contexto en el cual la consideración de una "culpabilidad previa" (Vorverschulden) podría, sin embargo, parecer evidente ${ }^{54}$. Es muy significativa en este sentido la permanente oposición de Jakobs a admitir ese recurso respecto del sujeto inimputable, precisamente a partir de consideraciones funcionales, pues en el comportamiento en estado defectuoso no puede verse racionalmente un ataque contra la vigencia de la norma, simplemente porque falta un sujeto de imputación, una persona definida como igual y con competencia para desautorizarla ${ }^{55}$. Tampoco desde esta perspectiva parecen admisibles entonces ficciones de culpabilidad.

El modelo de la excepción es, en consecuencia, una solución inaceptable en ordenamientos pretendidamente respetuosos del principio de culpabilidad, tanto más si, como se ha postulado para el derecho chileno (supra 2), dicho principio goza de reconocimiento constitucional ${ }^{56}$.

éste ha sido provocado por el sujeto, situación para la cual expresamente se prevé una excepción al efecto exculpante ( $\$ 35$ I frase segunda StGB). En la medida, sin embargo, en que ni la ley ni la doctrina en Chile (véase, por todos, Cury, PG, p. 454 y ss.) restringen en ese sentido el alcance de la eximente equivalente de fuerza (moral) irresistible (art. $10 \mathrm{~N}^{\circ} 9 \mathrm{CP}$ ), no viene al caso pronunciarse al respecto.

52 Cabe llamar la atención en cuanto a la importancia que desde esta perspectiva puede llegar a tener el desarrollo de la distinción, hasta ahora recogida sólo minoritariamente, entre causas de exclusión de culpabilidad y causas de disculpa (Schuldausschließungsgrïnde, Entschuldigungsgrïnde), al respecto, por todos, Lenckner, Theodor en Schönke / Schröder, StGB-Kommentar, 26. Aufl., Beck, München 2001, Vor $\ 32$ Rdn. 108/109.

53 Así, por ejemplo, Hirsch, Actio libera, p. 179 y s., señala que en los supuestos de error de prohibición el sujeto cuenta en el momento de su conducta con la capacidad suficiente como para advertir que está obrando sin haberse informado especialmente sobre el status jurídico de la misma y es precisamente eso y no su actuar precedente lo que se le reprocha, mientras que en el caso del inimputable, por definición, esa capacidad -y, con ella, la posibilidad de un reproche legítimosimplemente no existe.

${ }^{54} \mathrm{Al}$ respecto Neumann, Ulfrid: Neue Entwicklungen im Bereich der Argumentationsmunster zur Begründung oder zum Ausschluß strafrechtlicher Verantwortlichkeit, ZStW 99 (1987), 567 (577 y ss.).

55 Jakobs, Günther: Strafrecht, AT, 2. Aufl., De Gruyter, Berlin - New York 1993, 17/58 y s., 17/64 y ss.; y El mismo, Actio libera, passim.

56 En general, este modelo no ha sido objeto de adhesión explícita en nuestra literatura, si bien parecen seguirlo Brito / Fainé, en Rivacoba y Rivacoba (editor), Actas, p. 158 y s.; y Náquira, T. I, p. 373, 454; en tanto que siembran dudas Politoff / Matus / Ramírez, PG, p. 309: "Las actiones liberae in causa constituyen, pues, una excepción al principio de que el hechor debe ser imputable al tiempo de ejecutar el hecho punible", y, siguiendo precisamente a Hruschka, p. 310: "la exigencia de juzgar lo doloso o culposo de la acción al momento de cometerse el delito..., no rige si el hechor mismo es responsable por la situación de inconsciencia o por los efectos de la autointoxicación en que él mismo se ha puesto, pudiendo evitarlo", no obstante que el resto de la exposición (p. 310 y ss.) 
Lo mismo cabe decir de las propuestas interpretativas que, sin reconocer abiertamente una excepción al principio de culpabilidad, llegan a resultados equivalentes por la vía de desconocer un aspecto central del mismo, como el de la necesaria coincidencia entre culpabilidad y hecho (principio de coincidencia o de simultaneidad). Las propuestas de este tipo son variadas, pero en general se caracterizan por construir de un modo más o menos artificial una coincidencia aparente entre conducta e imputabilidad, sea a través de una ampliación de la conducta relevante para el juicio de culpabilidad, integrando en él de modo variable la actio praecedens con la conducta defectuosa, sea ampliando el rango temporal de lo que puede considerarse culpabilidad "por el hecho". Basten algunos ejemplos, en muy breve síntesis ${ }^{57}$ :

Así, Spendel ha entendido que la conducta penalmente relevante es la provocación del estado defectuoso, pero hace depender su tipicidad de la circunstancia ulterior consistente en que el sujeto alcance, a través de comportamientos adicionales, el estadio de la tentativa ${ }^{58}$. La propuesta no explica, sin embargo, cómo un acto preparatorio -reconocido como tal por el autor- puede convertirse con efecto retroactivo en ejecución típica por obra de actos posteriores de ejecución que en sí no se consideran típicos. Manifiestamente se trabaja con un concepto de conducta típica diferente, más amplio, mediante el cual se pretende superar la disociación temporal entre hecho e imputabilidad.

A resultados similares llega Schmidhäuser con su "modelo del injusto". A partir de la distinción entre injusto material e injusto formal, el autor sostiene que los actos preparatorios -entre ellos la provocación del estado defectuoso- en cuanto dirigidos a la lesión del bien jurídico ya forman parte del injusto material, aunque no satisfagan todavía los requisitos formales de la punibilidad, que hacen al injusto formal. De esta forma logra apreciar en estos casos simultaneidad entre la imputabilidad y el injusto (material) ${ }^{59}$.

parece ubicarse dentro de un modelo de tipicidad (infra 3.2), apariencia que vuelve a nublarse cuando a la culpa in causa se le atribuye mero efecto atenuante respecto de un delito doloso (p. 314), el que, consecuentemente, sólo puede ser el realizado en estado defectuoso. Esto último rige también para Garrido, T. II, p. 224 y s.

57 Una presentación más detallada puede verse en Alcácer, Actio libera, p. 53 y ss. (bajo la denominación genérica "modelo de la ampliación"); véase también Diaz. Pita, Actio libera, p. 37 y ss.

58 Spendel, Günter en LK (11. Aufl.) \ 323a StGB Rdn. 21 y ss. (ya antes en LK [10. Aufl.] Rdn. 32 y ss.). También en otros escritos del mismo Spendel y de Herzberg que no se han podido tener a la vista. Adhería a este punto de vista, al menos hasta su vigésima edición Lackner, Karl: Strafgesetzbuch mit Erläuterungen, 20. Aufl., Beck, München 1993, \ 20 Rdn. 25 (ya a partir de la $23^{\circ}$ edición de 1999 el $\int 20$ es comentado por Kühb), quien adhiere abiertamente al modelo de la excepción).

59 Schmidhäuser, Eberhard: Die actio libera in causa. Ein symptomatisches Problem der deutschen Strafrechtswissenschaft, Vandenhoeck \& Ruprecht, Hamburg 1992, p. 25 y ss. Una síntesis con crítica pormenorizada en la recensión de Frister, ZStW 108 (1996), 645. 
Y algo parecido cabe decir, por último, del "modelo de la ampliación" de Streng, a pesar de partir de presupuestos totalmente opuestos. Este autor sostiene que la única conducta relevante es la realizada en el estado defectuoso, pero a la hora de examinar si ésta es culpable, considera también factores de culpabilidad -si bien inmediatamente referidos a ella- existentes con anterioridad a la misma, entre ellos la provocación culpable del estado defectuoso ${ }^{60}$. Llama la atención que uno de los propósitos declarados del autor sea evitar cualquier manipulación del injusto $^{61}$, al mismo tiempo que por la vía de una verdadera manipulación de la culpabilidad llega a consecuencias del todo equivalentes.

Pues bien, como se ha dicho, variantes teóricas como éstas y otras semejantes en su estructura ${ }^{62}$ resultan incompatibles con el principio de culpabilidad en la medida en que desconocen la exigencia consustancial de coincidencia entre culpabilidad y hecho. Al derecho penal sólo le puede interesar una culpabilidad por el hecho, esto es, coincidente con él, y en ningún caso una "culpabilidad" disociada de la conducta injusta ${ }^{63}$, una especie de fantasma que vaga en un limbo y que, en esa medida, está disponible, acomodaticiamente, como justificación aparente de cualquier manifestación de responsabilidad objetiva. En definitiva terminan identificándose, por sus consecuencias, con el modelo de la excepción, aunque sin la "honestidad" de éste ${ }^{64}$. Porque si algún mérito tiene el modelo de la excepción es el de mostrar en toda su radicalidad que bajo la apariencia pacífica de la actio libera in causa se esconden riesgos muy considerables para los principios básicos de legitimación del derecho penal, los que en buena medida son encubiertos por otras aproximaciones.

\footnotetext{
60 Streng, Franz: Der neue Streit um die "actio libera in causa", JZ 1994, 709 (711 y ss.); El mismo, "actio libera in causa" und Vollrauschstrafbarkeit - rechtspolitische Perspektiven, JZ 2000, 20 (22 y ss.). Streng propone una interpretación extensiva de la expresión -consagratoria del principio de coincidencia- "en la comisión del hecho" ("bei Begehung der Tat") del $\int 20$ StGB, a partir de una comprensión normativa de la culpabilidad (califica de "ingenua" y tributaria de una concepción psicológica la exigencia de simultaneidad estricta) y de matices de texto legal que permitirían entender que el derecho alemán maneja distintos conceptos de "comisión" en distintos contextos. Véase también El mismo: Schuld ohne Freiheit? Der funktionale Schuldbegriff auf dem Prüfstand, ZStW 101 (1989), 273 ( 310 y ss.).

61 Streng, JZ 2000, 20 (22).

${ }^{62}$ Entre las que cabría contar la opinión de autores que, sin perjuicio de sugerir adhesión a un modelo de tipicidad, lo complementan con la noción de una acción total comprensiva de ambos momentos de la autointoxicación, como ocurre entre nosotros con Garrido, T. II, p. 223, cuando sostiene que la imputación al sujeto debe realizarse "considerando su actuar como un todo, lo que permite atribuir el resultado típico a dolo o culpa, pues al iniciar su actividad era imputable" (énfasis agregados); o con Etcheberry, T. I, p. 288, cuando ve la especialidad de estos casos en que "el hombre, mediante su previsión intelectual y volitiva, ha incorporado a su acción los resultados delictivos. Así, los actos ejecutivos en sí mismos no serían voluntarios, pero la acción en la cual se incorporan sí lo sería, y por ende, habría responsabilidad para el que obra" (énfasis parcialmente agregados).

${ }^{63}$ Hirsch, Actio libera, p. 180 y s.; Roxin, ADPCP 1988, 21 (24); Cousiño, T. I, p. 535 y ss.

${ }^{64}$ En ese sentido, lo califica de "más honesto" Ambos, NJW 1997, 2296 (2297).
} 


\subsection{El modelo de la tipicidad}

A la hora de buscar una alternativa a la conducta en estado defectuoso como posible base de la responsabilidad penal resulta bastante natural recurrir a la única conducta plenamente imputable disponible en los casos de autointoxicación plena, cual es la provocación previa de aquel estado defectuoso, e intentar fundar en ella un eventual castigo en términos compatibles con los principios de garantía del derecho penal. En general, la constatación en la actio praecedens plenamente imputable de dolo o culpa respecto de los hechos posteriores a la misma ha servido desde antiguo para afirmar la responsabilidad penal en virtud de dicha conducta previa y no ya en virtud de la conducta en estado defectuoso. De ahí que desde una perspectiva estructural se suela hablar de un modelo de anticipación $n^{65}$.

En efecto, desde esta perspectiva, aparentemente mayoritaria en $\mathrm{Chile}^{66}$, la única actio relevante es la provocación del estado defectuoso, en tanto que la actividad realizada en dicho estado sólo constituye un eslabón del curso causal que conduce al resultado típico ${ }^{67}$. Los movimientos del inimputable no se diferencian mayormente de la trayectoria de la bala, del destino de la carta explosiva o de las reacciones del perro azuzado por su dueño para que ataque. La única peculiaridad de este caso estriba en que el instrumento a través del cual se llega al resultado típico es el propio agente en condición de inimputabilidad a consecuencia de la autointoxicación plena. Con razón se han destacado, entonces, las similitudes de esta forma de ver las cosas con la estructura de la autoría mediata en los casos en que el autor se vale de un inimputable para sus fines, pues en rigor aquí ocurre lo mismo, aunque el instrumento no sea un tercero, sino el propio agente ${ }^{68}$.

Ciertamente la solución parece inobjetable desde el punto de vista del principio de culpabilidad, toda vez que la responsabilidad penal se funda en una conducta plenamente imputable. Un juicio definitivo exige, sin embargo, más cautela, pues no puede descartarse que la referencia a la actio praecedens en este contexto no sea más que un recurso retórico para legitimar las mismas consecuencias a las que conduce el modelo de la excepción. No debe olvidarse que en aquel modelo es precisamente el recurso a la previa provocación voluntaria del estado defectuoso lo que funda la excepción al principio de culpabilidad. El riesgo

\footnotetext{
${ }^{65}$ Así, por ejemplo, Hruschka, JZ 1997, 22; Streng, JZ 1994, 709 (710); El mismo, JZ 2000, 20.

${ }^{66}$ Así Ortiz. Muñoz, Pedro: Curso breve de derecho penal (común y militar), s/e, Santiago 1947, p. 136 y s.; Novoa, T. I, p. 454; Cury, PG, p. 413; en principio también, a pesar de las mencionadas dudas que producen algunas de sus explicaciones (supra 3.1), Etcheberry, T. I, p. 288; Garrido, T. II, p. 223; Politoff / Matus / Ramírez, PG, p. 310 y ss.; y claramente adheriría al mismo si le asignara relevancia práctica al punto Cousiño, T. I, p. 527 y ss.

${ }^{67} \mathrm{Si}$ una vez aclarado esto se puede seguir hablando a su respecto de una "acción" es una cuestión que en este contexto resulta meramente terminológica.

${ }^{68}$ Entre nosotros, por todos, nítidamente ya Ortiz Muñoz, Curso, p. 136: "Del mismo modo que podemos emplear al loco o al ebrio como instrumento para realizar un fin, aprovechándonos de que en ellos la determinación por razonamientos no es normal, podemos emplear a nuestra propia persona colocándola en estado de intoxicación o embriaguez para ejecutar un plan preconcebido".
} 
que se corre con la asunción acrítica de esta nueva perspectiva es que en definitiva la responsabilidad se funde realmente en una culpa praecedens y no en una actio praecedens con características delictivas, con lo cual o bien se vulnera igualmente el principio de culpabilidad ${ }^{69}$, o bien, según la perspectiva, lo que no es mejor, se infringe el principio de exterioridad (cogitationis poenam nemo patitur), porque en rigor se castiga por los malos propósitos. La ambigüedad de muchos de los planteamientos teóricos mencionados a propósito del modelo de la excepción demuestra que se trata de un peligro real.

La única manera de fundar legítimamente una responsabilidad penal en la provocación del estado defectuoso sin que ocurra lo anterior pasa por asegurar que la actio praecedens efectivamente reúna en sí misma todos los requisitos que legitiman la imposición de una sanción penal. No basta entonces con que se trate de la conducta de un sujeto plenamente imputable al momento de su realización, sino que además debe tratarse de una conducta típica y antijurídica, en los términos del tipo penal realizado en el posterior estado defectuoso. Que esto es posible es, precisamente, lo que afirma el llamado -ahora desde una perspectiva materialmodelo de la tipicidad ${ }^{0}$. Si bien se mira, el modelo, como lo indica la propia denominación que sus partidarios prefieren darle, no hace más que recurrir a las reglas generales de imputación para fundar la responsabilidad penal, en la medida de lo posible conforme a dichas reglas. Las peculiaridades que justifican seguir hablando de un "modelo" de imputación no vienen dadas entonces por las reglas aplicables, sino exclusivamente por la especial estructura de los casos en cuestión, como, sin embargo, es normal en cualquier proceso mínimamente complejo de subsunción ${ }^{71}$. En este trabajo se asume como criterio correcto el que ofrece el modelo de la tipicidad, considerando que las objeciones dogmáticas que se le dirigen no son decisivas, sin perjuicio de lo que se diga sobre su potencial operativo (infra 4). A continuación se revisan las objeciones más importantes.

La principal objeción que debe afrontar el modelo de la tipicidad es que supuestamente pretendería fundar de un modo ilegítimo la responsabilidad penal en hechos que no han alcanzado el estadio de la tentativa, esto es, en meros actos preparatorios, con lo cual, en su afán por preservar el principio de culpabilidad,

\footnotetext{
${ }^{69}$ Sobre el papel de la culpa praecedens en la historia de la responsabilidad objetiva Hormazábal, LHCerezo, p. 781, 789, 791 y ss.

${ }^{70}$ En el debate comparado adhieren a este modelo, entre otros, Roxin, ADPCP 1988, 21 (26 y ss.); Hirsch, Actio libera, p. 181 y ss.; Jakobs, Actio libera, p. 225 y ss.; Alcácer, Actio libera, p. 105 y ss.; Demetrio Crespo, Eduardo: La tentativa en la autoría mediata y en la actio libera in causa, Comares, Granada 2003, p. 137 y ss.; y si bien no entiende adherir a él, en cuanto funda la imputación en la "provocación relevante" del estado defectuoso, también Joshi Jubert, Actio libera, p. 281 y ss. La calificaba de dominante en Alemania, todavía en 1997, Roxin, Claus: Strafrecht, AT I, 3. Aufl., Beck, München 1997, \ 20 Rdn. 56, con síntesis jurisprudencial, Rdn. 69 y ss.

${ }^{71}$ Como destaca Freund, Georg: Strafrecht AT, Springer, Berlin etc. 1998, \ 4 Rdn. 41, su única utilidad está en ampliar la perspectiva de análisis, superando el estrecho ámbito naturalístico de la conducta inmediatamente lesiva para hacerse cargo también de la posible relevancia penal del comportamiento previo.
} 
sacrifica el principio de exterioridad ${ }^{72}$. De lege lata cabría agregar que de ser esto efectivo la punición de la conducta estaría descartada sin más, por simple aplicación del art. $7^{\circ} \mathrm{CP}^{73}$.

La objeción no es decisiva si se considera la ya aludida identidad estructural existente entre los casos de autointoxicación plena y la autoría mediata. Si respecto de este último instituto se admite mayoritariamente la llamada "solución individual" (Einzellösung), conforme a la cual el principio de ejecución respecto del autor mediato se sitúa en el momento en que éste - sin necesidad de realizar él mismo los comportamientos que respecto de un autor inmediato constituirían tentativa - pierde el control sobre el instrumento ${ }^{74}$, y no recién cuando respecto de este último se aprecia un principio de ejecución en los términos que rigen para el autor inmediato ("solución global", Gesamtlösung)", lo mismo debería regir también para los casos de autointoxicación plena, con lo cual, en principio, no existirían obstáculos conceptuales para afirmar al menos la presencia de una tentativa punible $^{76}$.

En la medida en que los detractores de esta solución argumentan básicamente con la imposibilidad de ver una autoría mediata en lo que, en rigor, es un caso de autoría inmediata, a lo que suelen agregarse argumentos de texto legal en aquellos ordenamientos en que se regula expresamente la autoría mediata como la instrumentalización de "otro" 77 , basta con replicar que no es eso lo que está en discusión -pues en rigor no se está afirmando que la autointoxicación plena sea realmente una hipótesis de autoría mediata-, sino simplemente si existe o no una identidad estructural entre ambas instituciones que justifique la aplicación de las mismas soluciones interpretativas ${ }^{78}$. Mayor peso debe asignársele entonces, al

\footnotetext{
72 Entre otros Paeffgen, Hans-Ullrich: Actio libera in causa und \323a StGB, ZStW 97 (1985), 513 (519); Streng, ZStW 101 (1989), 273 (309); El mismo, JZ 1994, 709 (710); Salger / Mutz̧bauer, NStZ 1993, 561 (563); Alonso Álamo, ADPCP 1988, 55 (59 y s.); lo alerta también Cousiño, T. I, p. 535 y ss. 73 Así también Cousiño, T. I, p. 538; hablan expresamente, sin embargo, de la punición de actos preparatorios sin extraer esta consecuencia legal, Politoff / Matus / Ramírez, PG, p. 310.

${ }^{74}$ Entre nosotros siguen este criterio Garrido, Mario: Etapas de ejecución del delito. Autoría y participación, Editorial Jurídica de Chile, Santiago 1984, p. 125 y s. (sin distinguir siquiera entre autoría mediata y coautoría); Cury, PG, p. 608; Politoff / Matus / Ramírez, PG, p. 399; de otra opinión Náquira, Jaime: Autoría mediata y tentativa, RDPUCV XXVI (2005), sem. I, 125 (130 y ss.).

75 Sobre la discusión en general Roxin, Claus: Strafrecht, AT II, Beck, München 2003, \ 29 Rdn. 226 y ss. (habla de "solución individual modificada"); Stratenwerth, Günter: Strafrecht, AT I, 4. Aufl., Heymanns, Köln etc. 2000, \ 12 Rdn. 102 y ss.; también Náquira, RDPUCV XXVI (2005), sem. I, 125 passim.

76 Roxin, ADPCP 1988, 21 (28); Hirsch, Actio libera, p. 184 y ss.; Jakobs, Actio libera, p. 227; Demetrio Crespo, La tentativa, p. 138 y s.

77 Paeffgen, ZStW 97 (1985), 513 (518); Ambos, NJW 1997, 2296 (2297); Díaz Pita, Actio libera, p. 50. ${ }^{78}$ Así Alcácer, Actio libera, p. 106 y s. Debe considerarse que la autoría mediata carece casi siempre de una regulación legal completa y que las soluciones diferenciadas respecto de las que rigen para la autoría inmediata se han obtenido siempre interpretativamente. No se aprecia por qué no puede regir lo mismo para otro tipo de situaciones que también presentan una estructura peculiar.
} 
menos en principio, a las objeciones que apuntan a que la situación normativa no es equiparable o a que la equiparación conduce a resultados insatisfactorios.

Así, por ejemplo, se ha argumentado que, a diferencia de lo que ocurre con la autoría mediata, en los casos de autointoxicación plena el dominio del suceso no pasa a un tercero sino que siempre se mantiene en manos del mismo sujeto, olvidando, sin embargo, que el "dominio de la acción" que mantiene el plenamente autointoxicado en nada se diferencia del "dominio" que detenta cualquier otro inimputable cuando una persona distinta se sirve de él: en ambos casos es igualmente irrelevante, de modo que no puede verse en ello un obstáculo para apreciar una estructura equivalente a la de la autoría mediata ${ }^{79}$.

Más delicada parece ser la objeción fundada en que el paralelismo con la autoría mediata conduciría a que el modelo no tuviera aplicación en los casos en que aquella figura está descartada, como ocurriría, por ejemplo, con ciertos delitos de conducta especificada y, en particular, con los llamados delitos de propia mano ${ }^{80}$. Antes de cualquier comentario al respecto, conviene tener presente que, en rigor, ésta no constituye una objeción al modelo, en el sentido de negar su corrección, sino simplemente la constatación de ciertas consecuencias inherentes al mismo, que, por cierto, son susceptibles de diversa valoración político-criminal. Por lo mismo, perfectamente se puede sostener que, siendo la identificación con la autoría mediata la única vía para fundar legítimamente una responsabilidad penal en los casos de autointoxicación plena, sólo cabe aceptar las restricciones que fluyen de dicha identificación ${ }^{81}$. En ese contexto, la cuestión ahora es dilucidar qué tan graves son realmente las consecuencias prácticas de la identificación, y todo indica que, si efectivamente lo fueran, esto sería en una medida mucho menor que la postulada por sus críticos ${ }^{82}$. Es lo que se analiza a continuación:

\footnotetext{
${ }^{79}$ Así Roxin, ADPCP 1988, 21 (29), con referencias a Küper, también Jakobs, Actio libera, p. 226 y s., con referencias a Neumann y a Kindhäuser.

${ }^{80}$ Hruschka, JZ 1997, 22 (23); Streng, ZStW 101 (1989), 273 (310); El mismo, JZ 1994, 709 (710); Salger / Mutzbauer, NStZ 1993, 561 (565).

81 Así, abiertamente, Roxin, ADPCP 1988, 21 (27, 31 y s.); Jakobs, Actio libera, p. 219 y s. No resulta admisible, en cambio, la alegación que alcanza a esbozar Hirsch, Actio libera, p. 188; y El mismo: Anwendbarkeit der Grundsätze der actio libera in causa, NStZ 1997, 230 (231), haciendo valer precisamente que en estos casos en realidad no se trata de un tercero instrumentalizado sino que del mismo sujeto, lo que evidentemente es correcto desde un punto de vista fáctico, pero no normativo, que es el único que aquí interesa. Si se está por distinguir normativamente los diversos estadios de la conducta del sujeto, no se puede luego pretender eludir las consecuencias de la distinción negándola según necesidad. Críticos también Sánchez-Vera, Javier: El denominado "delito de propia mano", Dykinson, Madrid 2004, p. 124 y s.; Alcácer, Actio libera, p. 180 y s.

82 Si bien un fallo relativamente reciente del Tribunal Supremo Federal alemán (BGHSt 42, 235 [238 y s.], de 22 de agosto de 1996) ha declarado en general inaplicable la construcción a los delitos de mera actividad, provocando un importante impasse en el debate dogmático en ese país; al respecto, por todos, Lenckner, Theodor / Perron, Walter en Schönke / Schröder, StGB-Kommentar, S 20 Rdn. 35 y ss.
} 
Tratándose de delitos puramente resultativos, cuya conducta en sí es indiferente porque viene definida por su resultado ${ }^{83}$, el modelo de la tipicidad no tiene dificultades para ver en la autointoxicación plena la conducta típica en la medida en que ésta cree un riesgo prohibido de consumación. La pregunta es si lo mismo rige respecto de tipos penales en los que la conducta no se define simplemente por el resultado -en muchos casos ni siquiera se requiere un resultado- sino que viene determinada específicamente en la ley ${ }^{84}$. Adicionalmente, la cuestión viene erizada por la supuesta existencia de los llamados "delitos de propia mano", subcategoría de la anterior respecto de la cual se suele negar la posibilidad de una autoría mediata -lo que implicaría idéntica consecuencia para la autointoxicación plena- pero cuyos contornos y alcances, sin embargo, distan completamente de ser pacíficos.

Lo primero que cabe decir es que respecto de la categoría genérica de delitos con conducta especificada mayoritariamente no se ve en esa característica un obstáculo para la autoría mediata, toda vez que el único propósito expresado en la ley es que tales conductas indeseables no se realicen, siendo indiferente si las ejecuta corporalmente el autor o el instrumento del que se vale ${ }^{85}$. En cuanto a los llamados delitos de propia mano, puede advertirse en la literatura especializada incluso una tendencia minoritaria pero creciente a negar derechamente la real existencia de la categoría ${ }^{86}$, postura que, si bien puede resultar problemática en sus extremos, coincide en todo caso con lo que sí puede calificarse de tendencia dominante en orden a restringir al máximo la extensión del concepto, reservando su uso a unos pocos delitos - raros y en franca extinción- en los que el injusto se

\footnotetext{
${ }^{83}$ Es lo que ocurre, por ejemplo, con el homicidio o los daños, en la medida en que matar o dañar ("causar daño" dice la ley chilena) no es más que provocar de modo objetivamente imputable la muerte de una persona o el menoscabo material de una cosa, siendo absolutamente indiferente la forma en que esto se verifique.

${ }^{84}$ Como ocurre, por ejemplo, con la violación ("acceder carnalmente") o el hurto ("apropiarse"). Como se sabe, la distinción tiene incidencia en la problemática de la omisión impropia (en la medida en que algún sector de la doctrina ha sostenido que en estos casos aquélla no sería posible, porque el respectivo tipo penal sólo puede realizarse mediante la conducta activa determinada en la ley; al respecto Roxin, AT II, $\mathbb{S} 32 \mathrm{Rdn}$. 225; y entre nosotros, negando ese efecto respecto de la estafa, Hernánder, Héctor: Aproximación a la problemática de la estafa, en $A A$.VV.: Problemas actuales de derecho penal, Universidad Católica de Temuco, Temuco 2003, p. 165) y en materia de autoría y participación, de donde se proyecta, por la vía de la postulada equivalencia estructural con la autoría mediata, a los casos de autointoxicación plena.

85 Así, específicamente respecto de casos como los de la autointoxicación plena Roxin, ADPCP 1988, 21 (31); Jakobs, Actio libera, p. 218 y s.; y con alcances más amplios, negando totalmente la existencia de grupos de casos problemáticos Sánchez-Vera, Delito de propia mano, p. 125; Alcácer, Actio libera, p. 184 y ss.

${ }^{86}$ Una noticia sobre el debate provocado por Schubarth, en Roxin, AT $\int 25$ Rdn. 308 y ss.; y especialmente Sánchez-Vera, Delito de propia mano, passim; y bastante antes ya Maqueda Abreu, María Luisa: Los delitos de propia mano, Tecnos, Madrid 1992, passim; véase también Alcácer, Actio libera, p. 182 y ss.
} 
funda exclusivamente en la realización corporal de la conducta $^{87}$, tendencia restrictiva que también se puede apreciar en $\mathrm{Chile}^{88}$. De esta manera, las consecuencias asignadas a los delitos de propia mano tienden también a replegarse, con lo cual la aplicación del modelo de la tipicidad en casos de autointoxicación plena respecto de delitos de conducta determinada parece no enfrentar limitaciones significativas por ese concepto ${ }^{89}$.

En cambio, debería admitirse como una consecuencia menos satisfactoria del modelo la imposibilidad de reconocer un desistimiento voluntario en los casos de autointoxicación plena preordenada cuando en definitiva no se consuma el delito en cuestión. Pues aunque sea del todo imaginable que esto se deba a un abandono del curso causal típico susceptible de ser interpretado como expresión de la voluntad del plenamente intoxicado ${ }^{90}$ y se pueda alegar de modo más o menos convincente que para la "voluntariedad" del desistimiento no se exige la imputabilidad del que se desiste ${ }^{91}$, en concordancia con los principios de la autoría mediata, según los cuales el desistimiento del instrumento no puede atribuirse al hombre de atrás, tampoco en este caso el desistimiento en estado defectuoso puede consistentemente atribuirse al imputable que se abandonó a su suerte ${ }^{92}$. Como ya se ha dicho, si se construye el modelo sobre la base del paralelo con la autoría mediata, de lo cual se extrae un conjunto de consecuencias deseables que no podrían haberse obtenido por otra vía, no resulta admisible desligarse a voluntad de ese punto de partida cuando las restantes consecuencias inherentes al mismo resultan desagradables ${ }^{93}$ : el "desistimiento" del plenamente intoxicado no

${ }^{87}$ Como sería el caso paradigmático del incesto; al respecto, por todos, Roxin, AT II, $\ 25$ Rdn. 288 y ss.

88 Novoa, T. II (1966), p. 183; Cury, PG, p. 621 y s.; más dudoso, probablemente influido por la literatura tradicional española, Garrido, Etapas, p. 361. Un ejemplo significativo de la tendencia lo da la violación, delito respecto del cual mayoritariamente se admite la posibilidad de autoría mediata, así Rodríguez. Collao, Luis: Delitos sexuales, Editorial Jurídica de Chile, Santiago 2000, p. 167 y s.; Cox, Juan Pablo: Los abusos sexuales, Lexis-Nexis, Santiago 2003, p. 275 y ss.; Cury, PG, p. 622; de otra opinión, si bien con un ejemplo de inducción, Politoff / Matus / Ramírez, PE (2004), p. 251 (y no obstante reconocer co-autoría sin intervención material, PG, p. 416). Un excelente ejemplo de la plausibilidad de una violación por autoría mediata, aunque en la especie no se diera por acreditada, la ofrece en el derecho inglés el célebre caso "Morgan" (1975), resumido en Nino, Carlos S.: Los límites de la responsabilidad penal (trad. Navarro), Astrea, Buenos Aires 1980, p. 177 con nota 65

${ }^{99} \mathrm{Al}$ respecto Roxin, ADPCP 1988, 21 (31 y s.); Jakobs, Actio libera, p. 218 y ss.

${ }^{90} \mathrm{Al}$ respecto, con especial detalle, Alcácer, Actio libera, p. 128 y ss.

91 Así Roxin, ADPCP 1988, 21 (33 y s.), respondiendo a las críticas de Welp y Neumann, criterio concordante con el estado de la doctrina chilena en materia de desistimiento, tal como lo condensa Politoff, Sergio: Los actos preparatorios del delito, tentativa y frustración, Editorial Jurídica de Chile 1999, p. 232 y ss. En España sigue a Roxin en este punto Demetrio Crespo, La tentativa, p. 141 y s.

${ }^{92}$ Jakobs, Actio libera, p. 227 y s.; criticando la inconsistencia de otros representantes del modelo de la tipicidad Hruschka, Actio libera in causa y autoría mediata, p. 167 y s.

${ }^{93}$ Como hace Hirsch, Actio libera, p. 187 con nota 45, cuando aduce que, por tratarse de la misma persona, el desistimiento en calidad de instrumento siempre favorece al sujeto. 
pasa de ser desviación del curso causal, relevante para la consumación, pero no para la punibilidad de las formas imperfectas de ejecución.

Ahora bien, desde un punto de vista de la llamada tipicidad subjetiva, el modelo de la tipicidad permite resolver convincentemente las cuestiones discutidas en ese plano:

La circunstancia de centrar todo el examen en la tipicidad de la provocación del estado defectuoso resuelve de manera nítida la cuestión sobre el objeto del dolo: éste debe abarcar tanto la provocación del estado defectuoso como la ulterior realización, en ese estado, del tipo objetivo de un delito ("doble dolo") ${ }^{94}$. No se requiere, en cambio, que la conducta realizada en el estado defectuoso sea también dolosa ("triple dolo") ${ }^{95}$, toda vez que el comportamiento en estado defectuoso y sus consecuencias son simplemente parte del curso causal, de suerte que carece de todo sentido normativo pretender imponerle exigencias subjetivas. Las únicas exigencias subjetivas son las que gravan la conducta típica, entre ellas la previsión y - eventualmente, según la convicción dogmática - la aceptación del resultado y del curso causal que conduce a él. La forma en que en definitiva se produzca éste - "dolosa" o "imprudentemente"- sólo merece consideración a título de posible desviación del curso causal ${ }^{6}$, debiendo destacarse, sin embargo, que las desviaciones realmente relevantes deberían concentrarse en los aspectos objetivos del desarrollo de los acontecimientos ${ }^{97}$.

Por otra parte, el modelo se aviene perfectamente con la forma normal de fundar responsabilidad en los delitos imprudentes, ya que por simple aplicación de las "reglas generales" de imputación se puede apreciar en la autointoxicación plena provocada bajo ciertas circunstancias una infracción de deberes de cuidado y, con ello, una conducta imprudente ${ }^{98}$. Así, nadie dudaría que el encargado del control de tráfico aéreo que se autointoxica plenamente y que en ese estado no realiza las actividades necesarias para evitar un accidente o las realiza mal, es responsable por dicho accidente, no ya por las acciones u omisiones realizadas en el estado defectuoso, sino porque la autointoxicación durante su turno representa en sí misma una infracción de sus deberes de cuidado a la que puede imputarse el accidente. Otra consecuencia de la mayor importancia es que por esta vía sólo puede castigarse la realización de tipos penales para los cuales la ley prevé expresamente la comisión culposa. Así, por ejemplo, la realización del tipo penal

\footnotetext{
${ }^{94}$ Joshi Jubert, Actio libera, p. 401; Alcácer, Actio libera, p. 140; en Chile Brito / Fainé en Rivacoba y Rivacoba (editor), Actas, p. 158 y s.; Garrido, T. II, p. 223; Politoff / Matus / Ramirez, PG, p. 314.

95 Así, sin embargo, Joshi Jubert, Actio libera, p. 404 y s.

${ }^{96} \mathrm{Al}$ respecto, con detalle, Alcácer, Actio libera, p. 142 y ss.

${ }^{97}$ Entre nosotros han puesto de relieve la importancia de posibles desviaciones del curso causal para la atribución a título de dolo Politoff / Matus / Ramírez, PG, p. 311 y s.

98 Roxin, ADPCP 1988, 21 (26); Joshi Jubert, Actio libera, p. 393 y s.; Hirsch, Actio libera, p. 182 y s.; Alcácer, Actio libera, p. 149 y ss. Entre nosotros Ortiz Muñoz Curso, p. 136; Novoa, T. I, p. 454; Etcheberry, T. I, p. 288; Brito / Fainé en Rivacoba y Rivacoba (editor), Actas, p. 159; Garrido, T. II, p. 223; Politoff / Matus / Ramírez, PG, p. 311.
} 
de violación o de abusos sexuales en estado defectuoso no podría ser sancionada si en la provocación del mismo no media dolo de parte del agente.

Tan extendida y arraigada se encuentra esta forma de entender la aplicación de los delitos culposos en estos casos que, aunque parezca paradójico, ha servido para acusar al modelo de tipicidad de no prestar ninguna utilidad en el ámbito de la imprudencia, de ser "superfluo"," sin advertir que si esto es así se debe exclusivamente a que en materia de imprudencia este modelo centrado en la tipicidad de la actio praecedens es el que se ha asumido desde siempre para resolver casos estructuralmente similares a los de la autointoxicación plena ${ }^{100}$. Consecuentemente, si algo merece el calificativo de "superfluo" en este contexto no puede serlo, como es obvio, el modelo al que de hecho se adscribe de modo virtualmente unánime, sino sólo la conservación de una doctrina particular -la de la actio libera in causa- para fundar lo que, en rigor, no es más que aplicación de principios generales de imputación.

En efecto, para concluir debe destacarse que para la aplicación del modelo de tipicidad la doctrina de la actio libera in causa resulta completamente superflua. Si la única conducta relevante para este modelo es la conducta de autointoxicación plena, que es desde todo punto de vista una actio libera in se, entonces carece de todo sentido la búsqueda de una conducta que sea libera in causa. La única que podría tener ese carácter es precisamente la actuación en estado defectuoso, que en este modelo, sin embargo, no es más que componente del curso causal que conduce al resultado y que, consecuentemente, no merece ser destacada. Y no sólo se trata de una doctrina superflua, sino que también perturbadora, pues el solo empleo de la expresión realza el lugar prominente de la conducta en estado defectuoso, sugiriendo inequívocamente una excepcionalidad que, con toda razón, se procura rechazar. Prueba de que se puede prescindir de la fórmula la da precisamente el recién mencionado tratamiento que se le da a los casos de autointoxicación plena en sede de imprudencia. Pero lo mismo debería regir también para los delitos dolosos, en la medida en que, como ha quedado de manifiesto, también a su respecto se aplican sólo "reglas generales", las que, cabe destacarlo, son, por lo demás, las únicas que legítimamente pueden aplicarse.

\section{Los límites operativos del modelo de la tipicidad}

Con todo, ya las dudas esbozadas en el apartado anterior en cuanto a la posibilidad de apreciar una tentativa punible en la provocación del estado defectuoso adelantan cuál es el verdadero problema que debe enfrentar esta construcción. Sintéticamente puede decirse que su potencial para fundar positiva y

\footnotetext{
${ }^{99}$ Diaz Pita, Actio libera, p. 175 y s. Entre nosotros Cousiño, T. I, p. 533 y s.; Cury, PG, p. 413.

100 Como lo ha destacado Alcácer, Actio libera, p. 167 y ss., se trata de los casos de "culpa por asunción" (Übernabmeverschulden), esto es, sintéticamente, conducta diligente fundada en actuar precedente imprudente.
} 
satisfactoriamente la responsabilidad penal es en extremo modesto, especialmente desde la perspectiva de la imputación objetiva.

Mientras en otras épocas probablemente tanto la amplitud de los resultados del examen de mera causalidad como la ausencia de razones poderosas en estos casos para la aplicación de correctivos normativos a la misma contribuían a que no se apreciaran mayores dificultades al respecto, tales dificultades se tornan insoslayables en el contexto del examen normativo más fino que impone la imperante doctrina de la imputación objetiva. Y si bien no se trata de un problema que justifique un reparo desde el punto de vista de su legitimidad ${ }^{101}$, este importante límite práctico resiente su plausibilidad político-criminal y, con ello, las posibilidades fácticas de una solución genuinamente respetuosa de los principios jurídico-penales.

En efecto, para afirmar responsabilidad penal en estos casos se debe comprobar en primer término que la provocación del estado defectuoso ha creado un riesgo prohibido de consumación del tipo penal en cuestión y que el resultado típico importa la actualización de ese preciso riesgo prohibido. Y las más de las veces esto resultará altamente problemático.

Basta con pensar en el caso que para la doctrina tradicional entre nosotros resultaría más sencillo e indudable, cual es el de la autointoxicación preordenada a la comisión del delito, con seguridad porque el dolo del agente es manifiesto ${ }^{102}$. Pero, si bien se ve, lo realmente difícil será que se dé el necesario objeto del dolo, esto es, que en verdad se pueda apreciar en la autointoxicación plena una conducta objetivamente típica. Desde luego no por supuestas limitaciones impuestas por la literalidad de los tipos penales, del tenor "embriagarse no es matar" difícilmente se podrá apreciar la creación del riesgo prohibido que implica "matar" en sentido típico, y esto con total independencia de cuáles hayan sido los propósitos del agente. En la gran mayoría de los casos, desde una perspectiva $e x$ ante -la única relevante en esta materia- el curso de los acontecimientos posteriores aparece como algo tan azaroso que impide un pronunciamiento afirmativo de la imputación objetiva ${ }^{104}$. En rigor, desde la perspectiva de la fundación racional de la

\footnotetext{
${ }^{101}$ En ese sentido, las críticas contra el modelo de tipicidad sólo son válidas en la medida en que se traicionen sus presupuestos y límites, pero no respecto de su aplicación consecuente, conforme a la cual sólo se imputa lo que se puede legítimamente imputar.

102 Así, por ejemplo, Brito / Fainé en Rivacoba y Rivacoba (editor), Actas, p. 158 y s.

103 Así Alonso Álamo, ADPCP 1989, 55 (66, 81 y s.); Díaz Pita, Actio libera, p. 47 y ss.; y de algún modo también Cerezo Mir, José: Las eximentes de culpabilidad, en El mismo: Temas fundamentales del derecho penal, Rubinzal-Culzoni, T. I, Buenos Aires etc. 2001, p. 463, y en términos casi idénticos El mismo: La eximente de anomalía o alteración psíquica. Ámbito de aplicación, en El mismo, Temas fundamentales, p. 485, cuando acusa una confusión entre "norma" y "ley penal".

104 Así, si bien con énfasis en el aspecto subjetivo individual, Zaffaroni, Eugenio Raúl / Alagia, Alejandro / Slokar, Alejandro: Derecho penal, PG, Ediar, Buenos Aires 2000, p. 673. También con énfasis subjetivo, por la vía de destacar posibles desviaciones del curso causal previsto, en Chile Politoff / Matus / Ramírez, PG, p. 311 y s.
} 
responsabilidad penal, en la normalidad de los casos beber o drogarse para matar no se diferencia en mucho de convencer al tío rico para que dé un paseo solitario por un barrio peligroso o se interne en el bosque en día de tormenta, con el propósito de que ahí encuentre la muerte.

Sólo parece posible hablar de la creación de un riesgo prohibido en casos muy especiales, que combinen tanto un grado significativo de regularidad en el tipo de comportamientos a que conducen episodios de autointoxicación plena de características similares, sea en general, sea en particular respecto del agente, así como un contexto situacional que reduzca o mantenga relativamente estables las múltiples variables que pueden incidir en el desarrollo del comportamiento de un inimputable ${ }^{105}$. Nótese que por definición se está frente a un instrumento que actúa por impulsos propios y no en manos del agente, faltando incluso las posibilidades relativas de control que se conservan en la genuina autoría mediata, donde el autor eventualmente y en medida variable puede todavía guiar y rectificar las desviaciones del curso previsto para su instrumento, posibilidad que en la autointoxicación plena se acaba en el preciso instante en que se produce ${ }^{106}$. Por lo mismo, la plausibilidad de un juicio ex ante de peligro respecto de un instrumento sin control requiere un contexto relativamente controlado.

Es en esa medida en que debe discreparse de Alcácer cuando ve precisamente en la pérdida de control por parte del agente un aumento del grado de peligro que justifica, anticipadamente en comparación con las tentativas normales ${ }^{107}$, el merecimiento de pena, pues dicha pérdida de control, tanto más cuanto más lejos se ubique el resultado y a menos que esté suficientemente "compensada" por un contexto controlado, implica al mismo tiempo pérdida de plausibilidad en el juicio de peligro ${ }^{108}$. En este contexto específico, el peligro asociado a la pérdida de control del actuar del agente -ciertamente innegableexhibe características genéricas y difusas que más que a la imputación objetiva en el seno de delitos previstos por el derecho vigente, parecen servir a la justificación de lege ferenda de un delito de peligro abstracto (al respecto infra 5) que, sin embargo, el autor rechaza ${ }^{109}$.

\footnotetext{
105 Zaffaroni / Alagia / Slokar, PG, p. 673: "Sólo en casos muy excepcionales puede sostenerse que la conducta de embriagarse sea típica de tentativa: ... (b) En excepcionales casos de tipicidad activa, en que el agente, por reiteradas e invariables experiencias anteriores, sabe con altísima probabilidad cuál será su comportamiento (quien sabe que cada vez que se embriaga hurta ropas de los fondos de las casas vecinas, porque lo ha reiterado veinte veces con el mismo resultado)".

${ }^{106}$ Ha destacado este aspecto Paeffen, ZStW 97 (1985), 513 (518 y s., con nota 21).

107 Alcácer, Actio libera, p. 121 y s.

108 Por cierto no faltan en su excelente libro consideraciones sobre la mayor o menor plausibilidad de un juicio de peligro en los casos concretos (cfr. Alcácer, Actio libera, p. 122 y s.), pero los énfasis sugieren una apreciación mucho más "optimista" al respecto que la que se mantiene aquí, a lo que sin duda contribuye la relevancia legitimante que le asigna a la pérdida de control sobre el peligro. 109 Alcácer, Actio libera, p. 86 con nota 274.
} 
Si las exigencias puestas al juicio de peligro -que, cabe recordarlo, no son sino aquéllas generalmente reconocidas en materia de imputación objetivaparecen excesivas, debe tenerse en cuenta que conceptualmente de ellas depende que al bebedor o al consumidor de drogas con propósitos homicidas en general no se le impute un homicidio frustrado cada vez que, habiéndose autointoxicado, se queda en su casa sin hacer mal a nadie ${ }^{110}$. Todo indica que la posibilidad de castigo sólo resulta admisible cuando la autointoxicación plena en sí misma representa un peligro que merece ser tomado en serio. La circunstancia meramente fáctica de que el sistema penal nunca se haga cargo de aquellos casos en los que la autointoxicación plena no conduce a ningún resultado lesivo no autoriza a perderlo de vista, pues, como debería ser evidente, el que lamentablemente en el caso particular haya ocurrido "algo" no puede modificar el juicio ex ante que debe presidir el examen de la imputación objetiva. La aplicación de un criterio distinto, que con seguridad no se estaría dispuesto a aceptar con carácter general, sólo puede explicarse como una reacción ante el hecho indeseable de la autointoxicación plena y sus desgraciadas consecuencias, reacción que, sin embargo, no es conciliable con los criterios de legitimación del derecho penal.

Algo similar ocurre con los delitos culposos. Debe recordarse que el campo de aplicación más relevante de la doctrina de la imputación objetiva ha sido precisamente el de los delitos imprudentes ${ }^{111}$, en tanto que la previsibilidad exigida dice relación con consecuencias concretas, en este caso, con delitos concretos susceptibles de ser objetivamente realizados en estado de intoxicación, sin que baste, como bien recuerdan Politoff, Matus y Ramírez, con el recurso genérico a la máxima de que "todos sabemos que debemos ser cuidadosos con la ingestión de alcohol"112.

Por último, cabe destacar que la aplicación del modelo conduce a la impunidad tratándose de delitos para los cuales la ley no ha previsto la comisión imprudente.

\section{Conclusiones y perspectivas de lege ferenda}

De las páginas precedentes se desprenden dos conclusiones que deberían ser tenidas en cuenta en cualquier intento por superar la deficiente regulación de la autointoxicación plena en el derecho vigente:

\footnotetext{
${ }^{110}$ Crítica habitual al modelo de la tipicidad; así, por ejemplo, Alonso Álamo, ADPCP 1989, 55 (60).

111 Como lo destaca, por ejemplo, Corcoy Bidasolo, Mirentxu: El delito imprudente, $2^{\circ}$ edición, Bdef, Montevideo-Buenos Aires 2005, p. 1 (sobre las exigencias de la imputación objetiva, p. 279 y ss.). Sobre la imputación objetiva en el delito culposo conforme al derecho chileno véase Bustos, Juan: El delito culposo, Editorial Jurídica de Chile, Santiago 1995, p. 79 y ss. (como elemento del juicio de antijuridicidad en su concepción).

112 Politoff / Matus / Ramirez, PG, p. 314.
} 
En primer lugar, que de todos los modelos ideados para fundar una responsabilidad penal por el hecho realizado en un estado defectuoso autoprovocado, el llamado modelo de la tipicidad parece ser el único que realmente se ajusta a las exigencias del principio de culpabilidad. En la medida en que dicho principio puede considerarse consagrado como garantía fundamental en el ordenamiento constitucional chileno, debería consecuentemente concluirse, además, que la introducción de cualquier variante de un modelo de excepción o de cualquier otro que conduzca a similares resultados estaría constitucionalmente vedada en el derecho chileno. En segundo lugar, que el potencial del modelo para satisfacer las demandas de represión penal en casos de autointoxicación plena están con seguridad muy por debajo de lo que probablemente son las expectativas sociales al respecto.

Estas conclusiones perfilan los desafíos que deben abordarse a la hora de revisar el derecho vigente sobre la materia. Primero, cómo debe expresarse en la ley el modelo de tipicidad, supuesto, en todo caso, que sea necesaria una consagración explícita. Segundo, cómo se debe reaccionar frente a la autointoxicación plena que no encuentra respuesta suficiente a través de dicho modelo.

Respecto de lo primero, esto es, cómo debería expresarse en la ley la adhesión al modelo de la tipicidad, probablemente la respuesta más consecuente y limpia es el silencio, la ausencia de regulación expresa. En efecto, si la solución del modelo consiste en la aplicación lisa y llana de las reglas generales de imputación en la medida en que en el caso concreto estén realmente disponibles los factores que permiten la aplicación de tales reglas, la ley no necesita decir nada más. Más aún, la experiencia comparada demuestra que el silencio legal opera como una importante barrera para la tentación de introducir soluciones que vulneren los principios de garantía del derecho penal. En el caso del derecho alemán, por ejemplo, el argumento decisivo contra el modelo de excepción ha sido siempre en último término su incompatibilidad no sólo con el principio de culpabilidad, sino que el propio principio de legalidad ${ }^{113}$, lo que, a la luz de la magnitud de las tentaciones, ciertamente no es poco.

La única razón por la que eventualmente podría ser conveniente, al menos entre nosotros, considerar una suerte de consagración expresa del modelo dice relación con una larga tradición de represión más o menos indiscriminada de los comportamientos desplegados en estado de intoxicación plena, en virtud de la fórmula "por causas independientes de su voluntad". En ese contexto, la ciertamente necesaria- supresión de dicha fórmula sin una nueva declaración que la reemplace podría conducir a una interpretación radical que prescindiera totalmente del castigo en casos de autointoxicación plena, sin darse el trabajo de verificar

\footnotetext{
113 BGHSt 42, 235 (241 y s.); Roxin, ADPCP 1988, 21 (23 y s.); Salger / Mutzbauer, NStZ 1993, 561 (565); Paeffen, ZStW 97 (1985), 513 (522, 524); Ambos, NJW 1997, 2296 (2297); Hirsch, Actio libera, p. 175. El propio Hruschka, JZ 1996, 64 (67 y s.) lo ha reconocido así, promoviendo desde entonces la consagración legal de su modelo, a través de una modificación del $§ 20$ StGB.
} 
previamente la relevancia penal de la actio praecedens a la luz del tipo en cuestión. O bien podría ocurrir al revés, esto es, que en ausencia de toda disposición legal la jurisprudencia asuma, más por inercia que por consenso, el modelo de excepción envuelto en el sentido natural y obvio de la doctrina de la actio libera in causa, tal como al parecer ocurre en la Argentina o en el Perú. Desde luego se trata de un riesgo que podría conjurarse suficientemente mediante constancias en ese sentido en los registros del proceso legislativo, sumadas al siempre necesario trabajo de elaboración dogmática, que en un nuevo escenario legal debería poder desplegarse adecuadamente. Pero es posible que para algunos estos resguardos no resulten suficientes.

De imponerse el criterio de ser necesaria una regulación expresa, debe tenerse en todo caso el cuidado de no terminar consagrando por esa vía alguna variante del modelo de la excepción, que, como se ha sostenido, no sería compatible con la garantía constitucional de un derecho penal de culpabilidad. En este sentido puede servir de advertencia la solución consagrada en el art. $20 \mathrm{~N}^{\circ} 2$ del Código penal español de 1995, que en lo que aquí interesa dispone ${ }^{114}$ :

"El que al tiempo de cometer la infracción penal se halle en estado de intoxicación plena por el consumo de bebidas alcohólicas, drogas tóxicas, estupefacientes, sustancias psicotrópicas u otras que produzcan efectos análogos, siempre que no haya sido buscado con el propósito de cometerla o no se hubiese previsto o debido prever su comisión...”"115.

A pesar de los ingentes esfuerzos de un sector de la doctrina penal española ${ }^{116}$, resulta sumamente difícil no reconocer que la fórmula legislativa consagra un modelo de excepción, como se desprende de modo inequívoco del hecho de que lo que se exceptúa es precisamente la exención de responsabilidad penal del que se encuentra privado totalmente de razón, extremo al que desde luego no llega el modelo de tipicidad. Lo único que puede decirse con arreglo a

\footnotetext{
${ }^{114}$ Una buena exposición del desarrollo histórico de la legislación peninsular en este punto hasta el Código de 1995 puede verse en Obregón García, Antonio: La eximente de estado de intoxicación plena por consumo de alcohol u otras drogas, RDPC, $\mathrm{N}^{\circ} 1$ extraordinario (2000), 275 (283 y ss.). ${ }^{115} \mathrm{La}$ norma reitera el principio consagrado en el inciso segundo del $\mathrm{N}^{\circ} 1$ del mismo art. 20, que regula, ahora separadamente, el transtorno mental transitorio: "El trastorno mental transitorio no eximirá de pena cuando hubiese sido provocado por el sujeto con el propósito de cometer el delito o hubiera previsto o debido prever su comisión. El trastorno mental transitorio no eximirá de pena cuando hubiese sido provocado por el sujeto con el propósito de cometer el delito o hubiera previsto o debido prever su comisión”. La parte no transcrita del $\mathrm{N}^{\circ} 2$ del art. 20 se refiere, con dudoso acierto sistemático, a las consecuencias del síndrome de abstinencia: “... o se halle bajo la influencia de un síndrome de abstinencia, a causa de su dependencia de tales sustancias, que le impida comprender la ilicitud del hecho o actuar conforme a esa comprensión". Esta última situación, no prevista expresamente en nuestro derecho, debe, sin embargo, entenderse cubierta por la eximente de fuerza (moral) irresistible del art. $10 \mathrm{~N}^{\circ} 9 \mathrm{CP}$. Al respecto, Hernández, Héctor: Las drogas ilegales en el derecho penal chileno (tesis PUC inédita), Santiago 1992, p. 341 y ss. 116 Alcácer, Actio libera, p. 96 y ss.; Demetrio Crespo, La tentativa, p. 127; para la situación anterior al Código de 1995 Joshi Jubert, Actio libera, p. 348 y ss.
} 
este modelo es que el sujeto imputable es responsable por lo que hace hasta el momento en que se provoca el estado defectuoso, pero no que el inimputable no está exento de responsabilidad, que es lo que de un modo literal consagra el precepto peninsular ${ }^{117}$. Otra cosa es, por cierto, que la doctrina se esfuerce por evitar una interpretación que conduce a consecuencias inadecuadas desde el punto de vista del principio de culpabilidad ${ }^{118}$, pero desde la perspectiva de lege ferenda se trata ciertamente de una formulación que habría que evitar ${ }^{119}$.

Más conveniente resultaría una referencia que aludiera a que la exención de responsabilidad por la privación total de razón -exención que no puede conocer excepciones- opera "sin perjuicio" de la responsabilidad que por el tipo en cuestión le pudiera caber al sujeto en virtud de la conducta realizada hasta la provocación del estado defectuoso. Con todo, sigue siendo preferible la prescindencia de regulación.

Respecto de lo segundo, la cuestión es ciertamente más compleja. Desde luego puede sostenerse que los límites del modelo de la tipicidad representan al mismo tiempo los límites de la intervención legítima del derecho penal en la materia, de suerte que lo que no se alcanza por esa vía simplemente debe asumirse como un asunto no susceptible de regulación penal. Por el contrario, el que parece ser el sector doctrinario mayoritario en el debate comparado se niega a la "resignación" en esta materia, en atención a lo que considera una ineludible necesidad político-criminal de dar una respuesta efectiva a la incidencia de la autointoxicación plena en la producción de resultados socialmente dañosos ${ }^{120}$.

\footnotetext{
117 Así lo admite, sea por razones de texto, sea por convicción dogmática, la literatura mayoritaria en España: Silva Sánchez, Jesús María: La estructura de la "actio libera in causa" en los delitos cometidos bajo un síndrome de abstinencia de drogas, LL 1988, 910 (914); Alonso Álamo, ADPCP 1989, 55 (62, 66 y s.); Muñagorri, ADPCP 1991, 413 (439, 441); Cerezo Mir, Las eximentes, p. 460 y ss.; El mismo, La eximente de anomalía, p. 482 y ss.; Sánchez Yllera, Ignacio, en Vives Antón, Tomás (coordinador): Comentarios al Código penal de 1995, Tirant lo Blanch, Valencia 1996, Vol. I, p. 121 y s.; Bustos / Hormazábal, Vol. II, p. 355 y s.; Muñoz Conde, Francisco / García Arán, Mercedes: Derecho penal, PG, $2^{\circ}$ edición, Tirant lo Blanch, Valencia 1996, p. 395; Morales Prats, Fermín, en Quintero Olivares, Gonzalo (director): Comentarios al nuevo Código penal, Aranzadi, Pamplona 1996, p. 144; Obregón García, RDPC No 1 extraordinario (2000), 275 (315); Diaz Pita, Actio libera, p. 183 y ss.; Padilla, Herminio: Algunas observaciones sobre la actio libera in causa en el derecho penal español, RECPC 03-04 (2001), 5.

118 Como se desprende nítidamente de la argumentación de Alcácer, Actio libera, p. 99 y ss.

119 Por lo mismo, cabría revisar el criterio impuesto en el Foro Penal, expresado en el ya citado art. $6^{\circ} \mathrm{N}^{\circ} 2$ ANCP.

${ }^{120}$ En rigor, los autores mayoritariamente no se ven en esta disyuntiva, porque entienden que el modelo al que adscriben responde adecuadamente a la demanda político-criminal. Lo que interesa destacar en este contexto es que la posible ausencia de reacción penal efectiva - "resignación" - no parece estar hoy dentro de las posibilidades admisibles. Como afirma Hirsch, Actio libera, p. 174: "nadie preconiza la impunidad".
} 
En ese contexto, viene en consideración como posible paliativo ${ }^{121}$ la eventual introducción de tipos penales especiales que se hagan cargo específicamente de la conducta de autointoxicación plena, con fundamento en el peligro común que representa la pérdida de control de una fuente potencial de peligro $^{122}$. Las posibilidades de configuración de un tipo de peligro de estas características son muy variadas, especialmente en lo que dice relación con los posibles límites que pueden imponerse a su aplicación. Paradigmático en este sentido es, por cierto, en el derecho alemán, el $\int 323$ a StGB (embriaguez plena, Vollrausch $^{123}$, cuyos dos primeros incisos, que son los que aquí interesan, son del siguiente tenor:

“(1) El que dolosa o imprudentemente se embriague mediante bebidas alcohólicas u otros medios embriagantes, será castigado con privación de libertad de hasta cinco años o con multa, si en ese estado realiza un hecho antijurídico y no puede ser castigado por el mismo, porque a consecuencia de la ebriedad estaba o no puede excluirse que estuviera en estado de inimputabilidad".

“(2) La pena no podrá ser más grave que la pena prevista para el hecho cometido en estado de ebriedad".

Como se ve, se trata de un delito de peligro abstracto, que castiga el hecho mismo de ponerse dolosa o imprudentemente en una situación de inimputabilidad. La eventual comisión de un hecho antijurídico opera exclusivamente como una condición objetiva de punibilidad mediante la cual se evita la imposición de una sanción cuando la autointoxicación plena no tiene consecuencias delictivas, en tanto que la referencia a la pena prevista para el delito que se hubiera cometido de haberse actuado en situación de imputabilidad sirve de límite máximo para la pena ${ }^{124}$. Según opinión ampliamente mayoritaria el precepto sólo se aplica en forma subsidiaria, cuando el hecho no es punible conforme al tipo penal objetivamente realizado en estado de intoxicación plena ${ }^{125}$.

El $₫ 323 a$ StGB ha sido objeto de una crítica implacable tanto dentro como fuera de Alemania, básicamente porque en algunas de sus implicancias se le

121 Sólo con ese carácter, pues en general se considera que la única solución óptima se da a través del tipo realizado; así, por muchos, Hirsch, Actio libera, p. 174 y s.

${ }_{122}$ Ménder. Longoria, Derecho Penal Contemporáneo No 13 (2005), 5 (39 y ss.), ha sugerido para el derecho de los Estados Unidos la introducción de tipos específicos de intoxicación con penas más altas que las de los delitos imprudentes, pero más bajas que las que corresponden a los delitos dolosos cometidos en ese estado, precisamente para atender a las demandas político-criminales pero aliviando al mismo tiempo la presión sobre las exigencias subjetivas de los delitos.

${ }^{123}$ Muy similar al $\ 287$ StGB (volle Berauschung) del derecho austriaco (pena máxima de tres años; al respecto Fabrizy, Enst Eugen: Strafgesetzbuch samt ausgewählten Nebengesetzen, Manz, Wien 2002, \287) y al art. 263 CP del derecho suizo, que se reproduce más abajo.

${ }_{124} \mathrm{Al}$ respecto, por todos, Lackner, Karl / Kühl, Kristian: Strafgesetzbuch mit Erläuterungen, 23. Aufl., Beck, München 1999, §323a Rdn. 1, 5, 15.

125 Lackner / Kühl, \ 323a Rdn. 19; Cramer, Peter / Sternberg-Lieben, Detlev, en Schönke / Schröder, StGB-Kommentar, \323a Rdn. 4, 31a. 
considera incompatible con el principio de culpabilidad ${ }^{126}$. Muchas de las críticas son fundadas y aquí se comparten plenamente, pero debe mirarse con atención el origen de las mismas antes de emitir juicios definitivos, pues muchos de sus detractores pueden promover al mismo tiempo un modelo de excepción o entender el modelo de tipicidad de una forma que pasa por alto las exigencias de la imputación objetiva, con lo cual legitiman, además de infracciones a principios cardinales del derecho penal, la imposición de penas significativamente mayores.

Naturalmente no es sencilla la legitimación de un delito de peligro abstracto fundado en el simple consumo excesivo de sustancias embriagantes, especialmente cuando dicho consumo, al menos respecto de algunas de ellas, está permitido y es hasta promovido con intensidad en la sociedad ${ }^{127}$. Por su parte, cualquier argumento a partir de los delitos de conducción en estado de ebriedad alcohólica o bajo la influencia de sustancias estupefacientes o sicotrópicas (art. 196 E Ley del Tránsito) fracasa, en la medida en que aquí falta un contexto de riesgo tan nítido como el de la conducción, que incluso permite legitimar la represión sin que sea necesario que la intoxicación llegue a ser plena, en tanto que es dudoso que respecto de un tipo penal con vocación genérica se puedan definir condiciones especiales que permitan calificar el riesgo propio de la autointoxicación plena. La cuestión es, en definitiva, sí los riesgos asociados a la pérdida de control sobre la propia conducta tienen por sí solos una relevancia suficiente como para justificar un tipo penal ${ }^{128}$, lo que dista mucho de ser evidente.

Como sea, si se llegara a aceptar la admisibilidad de un delito de estas características, resultaría indispensable situar la pena en un rango que realmente corresponda a su carácter de delito de peligro abstracto, significativamente por debajo de la que corresponde al delito cuyo tipo objetivo se realiza en estado defectuoso ${ }^{129}$, pero probablemente también por debajo de lo que rige para delitos de peligro con fundamento más sólido, como ocurre con los mencionados delitos de conducción en estado de ebriedad ${ }^{130}$, y en todo caso, conservando como condición objetiva de punibilidad la efectiva realización del tipo objetivo de un delito, conservación que, si bien a primera vista puede parecer contradictoria con

\footnotetext{
126 Un panorama en Paeffgen, Hans-Ullrich, en Nomos-Kommentar zum Strafgesetzbuch, Nomos, Baden-Baden, Stand: 2000, \323a Rdn. 1 y ss. Una recepción de la crítica en Chile en Politoff, Sergio: Derecho penal, T. I, $2^{\circ}$ edición, ConoSur / LexisNexis, Santiago 2000, p. 434 y s.

$127 \mathrm{Al}$ respecto Renæikowski, Joachim: Die Verschärfung des \323a StGB - Preisgabe des Schuldprinzips, ZStW 112 (2000), 475 (507 y s.).

128 Afirmativamente Ren rikowski, ZStW 112 (2000), 475 (509).

129 Crítico respecto del derecho vigente en Alemania, con referencias a regulaciones y proyectos anteriores que situaban la pena en un rango claramente inferior (v. gr. máximo de 6 meses), Renzikowski, ZStW 112 (2000), 475 (513).

${ }^{130} \mathrm{Si}$ bien la mayor pérdida de control que implica que la intoxicación sea plena y la consideración, como en seguida se dirá, de una condición objetiva de punibilidad, podrían llegar a justificar una pena en el mismo rango.
} 
el fundamento del delito de peligro abstracto, no lo es desde la perspectiva del principio de proporcionalidad ni de las necesidades de prevención general ${ }^{131}$.

Sólo de esta manera se puede sostener seriamente que no se trata de una manera encubierta de castigar por el hecho realizado en estado defectuoso, sino que en verdad por el peligro común creado con la autointoxicación plena ${ }^{132}$. Es evidente que el eventual hecho en estado defectuoso es lo que se ha tenido en mente a la hora de formular el tipo, pero esta evidencia no pone en entredicho la afirmación precedente, pues ése es un rasgo común a todo delito de peligro. Lo realmente relevante es que el quantum del castigo se ubique en un rango significativamente más bajo y que éste sea independiente de lo que ya no es en rigor imputable al sujeto. Por lo mismo, mientras la conservación de una condición objetiva de punibilidad resulta adecuada, no ocurre lo mismo con la vinculación de la pena a la gravedad del hecho realizado en estado defectuoso, aunque sólo sea para los efectos de establecer su límite máximo, pues tal vinculación expresa inequívocamente la pervivencia de una calificación por el resultado ${ }^{133}$, sin contar con la inequidad que importa que sólo para el caso de producirse consecuencias muy graves las penas por la embriaguez sean con seguridad más bajas que las del delito que podría haber cometido un imputable, en tanto que tratándose de consecuencias menores las penas pueden ser las mismas, con quiebra, además, del principio de proporcionalidad ${ }^{134}$. La fijación de un marco penal bajo, unida eventualmente a una ampliación de la condición objetiva de punibilidad, permitiría prescindir de dicha vinculación sin riesgo de resultados desconcertantes, como sería que la realización no culpable de un tipo penal llevase aparejada, por la vía de la comisión de un delito de peligro abstracto, más pena que la realización plenamente culpable del mismo. En ese sentido, la fórmula del derecho suizo no debe despreciarse. El art. 263 del Código penal helvético dispone:

“(1) El que, encontrándose en estado de inimputabilidad causado por ebriedad o intoxicación debidas a su hecho, será castigado con prisión de hasta seis meses o multa".

\footnotetext{
131 Renqikowski, ZStW 112 (2000), 475 (515). La solución es similar, guardando las diferencias evidentes, a lo que se admite sin discusión respecto de los delitos imprudentes.

132 Interesantes reflexiones sobre si el $\int 323$ a StGB es realmente un tipo de la parte especial o, en rigor, una forma especial de culpabilidad en Dencker, Friedrich: \323a StGB - Tatbestands- oder Schuldform?, JZ 1984, 453.

133 Renzikowski, ZStW 112 (2000), 475 (514 y s.).

${ }^{134}$ Un efecto similar se ha producido recientemente en el derecho chileno con la Ley $\mathrm{N}^{\circ} 20.084$, de Responsabilidad Penal Juvenil, mediante el establecimiento de límites máximos a las penas privativas de libertad. En cuanto estos límites -en sí inobjetables, salvo por su "generosidad represiva"- no están coordinados con los criterios generales de determinación de pena, permiten que dos adolescentes de la misma edad reciban la misma pena por hechos de muy distinta gravedad. El sistema debería corregirse en el sentido de garantizar que esos límites se proyecten proporcionalmente a todos aquéllos que no se ven directamente favorecidos por los mismos.
} 
Hernández - El régimen de la autointoxicación plena en el Derecho Penal Chileno

“(2) La pena será de prisión si la reclusión es la pena única prevista por la disposición que reprime el acto cometido en ese estado".

Es posible que las reflexiones precedentes no sean del todo convincentes desde el punto de vista de los criterios de legitimación del derecho penal, a la vez que, en cuanto su aceptación conduce necesariamente a una reacción que, si bien permite llegar más allá que lo que se puede a través del modelo de la tipicidad, de todas maneras puede calificarse de muy moderada, probablemente no respondan tampoco a las demandas sociales de represión. Antes esto sólo cabe constatar la necesidad entre nosotros de un debate a fondo sobre el tema y replicar que éste requiere a la vez una mirada menos prejuiciada y más realista del asunto y una clara conciencia de los límites infranqueables para el derecho penal de un pretendido Estado de Derecho. Mientras tanto, el derecho penal chileno sigue en deuda con el principio de culpabilidad.

\section{$* * *$}

Este trabajo ha sido escrito como modesta pero muy sincera contribución al homenaje que en el Perú se ha querido brindar a Juan Bustos. Siempre abundan buenas razones para homenajear la carrera de un gran académico, y en el caso de una trayectoria y de una obra tan destacada como la de Bustos, esas razones parecen multiplicarse. A las mismas, sin embargo, quisiera agregar otras más personales.

Pertenezco a una generación de profesores chilenos de derecho penal que le debe mucho a Juan Bustos. Varios de nosotros emprendimos nuestros estudios de postgrado en el extranjero al poco tiempo de su retorno a Chile, lo que nos permitió contar con su consejo y, especialmente, con una recomendación suya que de modo invariable nos abrió muchas puertas, tal como antes había ayudado a otros -recibiéndolos y dirigiendo sus estudios en Barcelona, o bien apoyando su inserción en otro lugar- y como hoy sigue apoyando a las generaciones más jóvenes. Pero con independencia de eso, para muchos de quienes vivimos la universidad chilena de las postrimerías de la dictadura militar, aunque hubiésemos gozado -especialmente en nuestros cursos de derecho penal- de algunos espacios de reflexión genuinamente universitaria sobre los fundamentos y los principios de un Estado de Derecho en medio del oscurantismo y del sectarismo reinantes, la figura de Juan Bustos y su brillante trayectoria académica (sus dos doctorados y las circunstancias de los mismos, sus libros, su cátedra española, los proyectos de primera línea de que formaba parte) de la mano de la persecución política que había sufrido y del exilio que todavía sufría, alcanzaba ribetes de leyenda y, en alguna medida, de símbolo en el que se entrelazaban los sueños individuales de unos aprendices de académicos y los anhelos colectivos de un país que quería reconquistar su democracia. Afortunadamente la democracia volvió y Juan Bustos dejó de ser una leyenda para convertirse en una presencia familiar, sencilla y hospitalaria, al punto que con los años esas impresiones del pasado empiezan a 
REJ - Revista de Estudios de la Justicia - No 9 - Año 2007

borrarse. Hasta ahora, cuando este homenaje permite refrescar los recuerdos y darse tiempo para el agradecimiento que se merece un gran maestro.

A la hora de elegir un tema para esta contribución me pareció adecuado abordar un problema de la parte general, particularmente uno del ámbito del principio de culpabilidad y de la categoría misma de la culpabilidad, por ser éste un objeto de atención permanente del homenajeado ${ }^{135}$. Me temo que las conclusiones de este trabajo no coinciden con la posición que ha defendido sobre la autointoxicación plena ${ }^{136}$, pero sé positivamente que éste no es un inconveniente: Juan Bustos nunca ha sido amigo de la obsecuencia y sabe, además, del respeto y admiración que, aun en la discrepancia, se le prodiga.

135 Véase Bustos, Juan / Soto, Eduardo: "Voluntaria" significa culpabilidad en sentido restringido, RCP T. XXIV (1964), 243; Bustos, Juan: Imputabilidad y Estado de Derecho, en El mismo: Bases críticas de un nuevo derecho penal, Temis, Bogotá 1982, p. 87 y ss., entre otros.

136 Bustos / Hormazábal, Vol. II, p. 355 y s. 